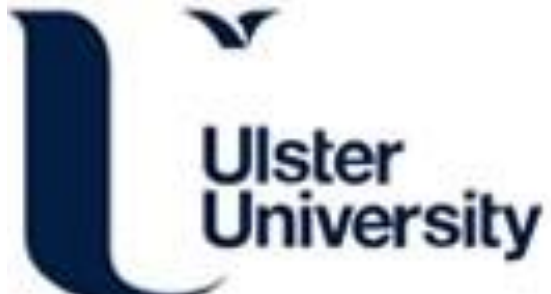

\section{Strontium substituted hydroxyapatite promotes direct primary human osteoblast maturation}

Stipniece, L., Wilson, S., Curran, J. M., Chen, R., Salma-Ancane, K., Sharma, P., Meenan, BJ., \& Boyd, A.

(2021). Strontium substituted hydroxyapatite promotes direct primary human osteoblast maturation. Ceramics International, 47(3), 3368-3379. https://doi.org/10.1016/j.ceramint.2020.09.182

Link to publication record in Ulster University Research Portal

\section{Published in:}

Ceramics International

Publication Status:

Published (in print/issue): 01/02/2021

DOI:

10.1016/j.ceramint.2020.09.182

\section{Document Version}

Author Accepted version

\section{General rights}

Copyright for the publications made accessible via Ulster University's Research Portal is retained by the author(s) and / or other copyright owners and it is a condition of accessing these publications that users recognise and abide by the legal requirements associated with these rights.

\section{Take down policy}

The Research Portal is Ulster University's institutional repository that provides access to Ulster's research outputs. Every effort has been made to ensure that content in the Research Portal does not infringe any person's rights, or applicable UK laws. If you discover content in the Research Portal that you believe breaches copyright or violates any law, please contact pure-support@ulster.ac.uk. 
Title: Strontium substituted hydroxyapatite promotes primary human osteoblast maturation

Authors: L. Stipniece ${ }^{\mathrm{a}}$, S. Wilson ${ }^{\mathrm{b}}$, J.M. Curran ${ }^{\mathrm{c}}$, R. Chen ${ }^{\mathrm{d}}$, K. Salma-Ancane ${ }^{\mathrm{a}}$, P.K. Sharma ${ }^{\mathrm{b}}$, B.J. Meenan $^{\text {b and A.R. Boyd }}{ }^{\mathrm{b}}$

\section{Affiliations:}

a - Rudolfs Cimdins Riga Biomaterials Innovations and Development Centre of RTU, Institute of General Chemical Engineering, Faculty of Materials Science and Applied Chemistry, Riga Technical University, Pulka 3, Riga, LV-1007 (Latvia).

b - Nanotechnology and Integrated Bioengineering Centre (NIBEC), School of Engineering, Ulster University, Shore Road, Newtownabbey, Co. Antrim. BT37 0QB. (UK).

c - School of Engineering, University of Liverpool, Liverpool L69 3BX, (UK).

d - Centre of Excellence for Biofilm Science (CEBS), 5D Health Protection Group Ltd., Liverpool, (UK).

\section{Corresponding Author: Adrian R. Boyd}

\section{ar.boyd@ulster.ac.uk}

Tel: +44 (28)90368924

Nanotechnology and Integrated Bioengineering Centre (NIBEC),

School of Engineering, Ulster University,

Shore Road, Newtownabbey, Co. Antrim. BT37 0QB. UK. 


\begin{abstract}
Strontium-substituted hydroxyapatite (SrHAp) materials are known to actively promote bone formation. However, the optimum level of $\mathrm{Sr}$ inclusion needed to elicit a physiologically relevant response from bone cells is unclear and can vary dependent on the fabrication process employed. In this work hydroxyapatite (HAp), SrHAp powders (2, 5 and $10 \mathrm{wt} \%$ (i.e., 1, 2 and 5 at\%) with respect to $[\mathrm{Sr} /(\mathrm{Sr}+\mathrm{Ca}) \cdot 100])$, were synthesized with the purity and Sr-substitution was confined in the range of 1-8 wt\% (1-4 at\%). All SrHAp samples contained rod-like crystals (<106nm in length), which decreased in length with increasing Sr content, and exhibited larger flatter crystals (>300nm in length). TEM-EDX confirmed the presence of Sr and maintenance of the HAp lattice structure for both types of crystals. Qualitative in vitro evaluation using primary human ostesoblast cells (HOBC) cultured in contact with the SrHAp over 28 days showed that the presence of $\mathrm{Sr}$ (in particular with the highest $\mathrm{Sr}$ content) directly promotes the maturation of osteoblasts into osteocytes as compared to the response observed for HAp. As these materials contain no additives other than $\mathrm{Sr}$, the effects observed here can only be attributed to the physiologically important levels of $\mathrm{Sr}$ in the samples.
\end{abstract}

Keywords: strontium substitution, hydroxyapatite, osteoblast, osteocyte, collagen I 


\section{Introduction}

Effective bone regeneration remains a significant clinical challenge and advantageous strategies to enhance bone defect healing are still urgently needed. Hydroxyapatite (HAp) has been widely used in the biomedical fields in applications such as implant coatings, fillers for bone substitutes and as drug carriers for controlled release. Its widespread application is due to its biocompatibility, bioactivity and similarity to bone mineral component [1]. Today bone graft materials are expected not only to facilitate the growth of as replacement tissue after disease, injury, or failure due to ageing, but also to provide for the delivery of biologically active substances, which act against the causative disease of bone loss [2]. Extensive work has been carried out on the development of biomaterials combined with components that specifically promote bone growth, e.g. growth factors and bone morphogenetic proteins. However, the need for high concentrations to maintain a therapeutic efficiency increases costs of the therapy and generates serious concerns over long-term complications associated with the high dosages of the biological molecules [3]. Thus, the substitution of other more biologically active ions such as $\mathrm{Na}^{+}$, $\mathrm{Mg}^{2+}, \mathrm{K}^{+}, \mathrm{Sr}^{2+}, \mathrm{Zn}^{2+}, \mathrm{Ba}^{2+}, \mathrm{Al}^{3+}$ etc. for $\mathrm{Ca}^{2+}$ into bone graft materials, including HAp, provides a feasible solution for bone defect healing [4]-[6]. Substitutions for $\mathrm{PO}_{4}{ }^{3-}$ and $\mathrm{OH}^{-}$ions are also possible, for example silicon $\left(\mathrm{SiO}_{4}{ }^{4-}\right)$ and carbonate $\left(\mathrm{CO}_{3}{ }^{2-}\right)$ [7]. The advantages of such a strategy are lower costs, greater simplicity, higher stability, and more efficacies at low concentrations [8]. Strontium $(\mathrm{Sr})$ is a unique biologically active trace element that simultaneously stimulates bone formation while inhibiting bone resorption [9]. It has been reported that $\mathrm{Sr}$ increases pre-osteoblast proliferation, osteoblast differentiation, type I collagen synthesis and bone matrix mineralization and inhibits osteoclast differentiation and activation [9], [10]. 
Typically, $\mathrm{Sr}$ is found in bone at very low concentrations of between $0.008-0.01$ at $\%$ but can be found at concentrations of between 3 and 7 at $\%$ where bone is actively metabolising [7], [11]. The latest advances in Sr based regenerative therapies have been reviewed by Jimenez et al [10]. Given the positive biological properties of $\mathrm{Sr}$ in bone remodelling, it has been used in many studies as an additive to various biomaterials, including bioactive glasses [12], [13] and calcium phosphates $(\mathrm{CaP})$ [12], [14]. Sr incorporation into different CaP-based biomaterials are highly promising for providing appropriate support to a defective site and delivering biologically active components to encourage bone tissue regeneration. Moreover, in vivo studies showed that Srdoped $\mathrm{CaP}$ cements and bioceramic materials promote bone regeneration [15], [16]. Previously, the drug strontium ranelate (SrRan) was used to treat osteoporosis, however, it was subsequently withdrawn from use in 2017 in Europe due to concerns it increased the chances of myocardial infarction in patients [17]. As such, there is a clear need to provide more localised delivery of $\mathrm{Sr}$ into bone defects, to administer the required therapeutic effect. Further to this, there is still disagreement in the literature as to the appropriate (and minimum) concentration of $\mathrm{Sr}$ to be effective without provoking any negative consequences [18], [19].

The aim of this work was to manufacture a range of Sr-substituted HAp materials with physiologically relevant levels of $\mathrm{Sr}$ and to study their effect on primary human osteoblast cells (HOBC). Specifically, the work has focused on low concentrations of Sr substitution of the HAp to determine an effective minimum dosage to inform future work. The physicochemical properties and level of ionic substitution of each sample were compared using atomic absorption spectrometry (AAS), Fourier transform infrared spectroscopy (FTIR), X-ray photoelectron spectroscopy (XPS), X-ray diffraction (XRD), scanning electron microscopy, energy dispersive X-Ray (EDX) analysis and transmission electron microscopy (TEM). Studies have shown that 
biocompatibility is very dependent on the cell type involved in the tests. This work utilizes primary human osteoblasts cells (HOBC) which provide more clinically relevant results and brings the translational process closer as the interspecies differences are circumvented [20].

\section{Materials and methods}

\subsection{Preparation}

HAp powders with 4 different Sr concentrations, namely, pure HAp (HAp), HAp with 2 wt $\% \mathrm{Sr}$ in respect to total content of cations, namely, Ca and $\mathrm{Sr}$ (2SrHAp), HAp with $5 \mathrm{wt} \% \mathrm{Sr}$ (5SrHAp) and HAp with 10 wt\% Sr (10SrHAp) were synthesised via aqueous precipitation described in detail previously [21]. Briefly, the main steps are shown in Figure 1.

The powders were uniaxially pressed at $10 \mathrm{kN}$ into cylindrical moulds using $0.3 \mathrm{~g}$ of powder per disk (13 mm x $1 \mathrm{~mm})$ and were sintered at $600{ }^{\circ} \mathrm{C}$ for $2 \mathrm{~h}$ using heating rate at $2{ }^{\circ} \mathrm{C} / \mathrm{min}$ up to $600{ }^{\circ} \mathrm{C}$, followed by cooling rate at $2{ }^{\circ} \mathrm{C} / \mathrm{min}$ to room temperature. 


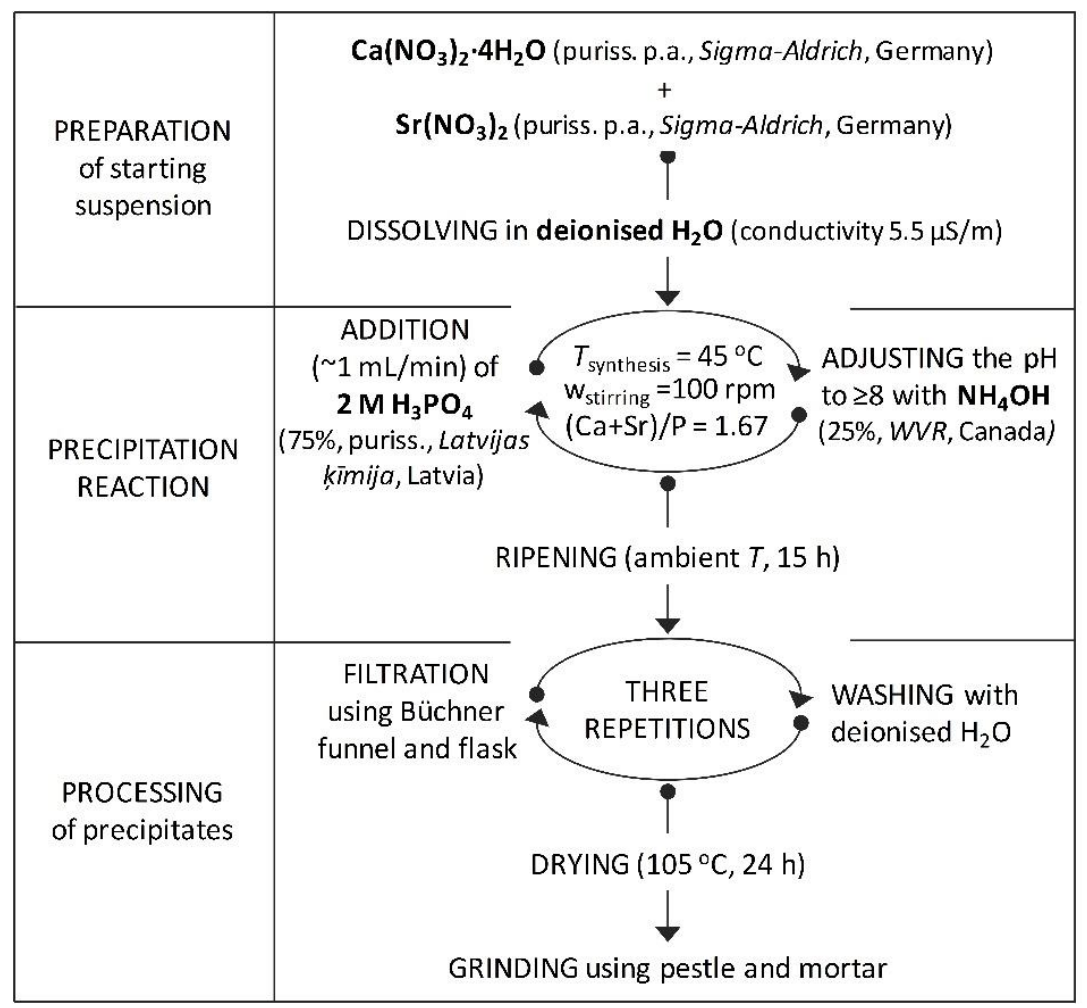

Figure 1. The main steps and technological parameters of the HAp powders synthesis.

\subsection{Physico-chemical characterization}

Atomic absorption spectrometry (AAS, Varian SpektrAA 880, Australia) was performed using electrothermal atomization according to the LVS ISO 11047:1998 standard test method.

X-ray photoelectron spectroscopy (XPS) was performed using an AXIS Ultra delay-line detector (DLD) spectrometer (Kratos, UK). Spectra were analysed using monochromated Al K $\alpha$ $\mathrm{X}$-rays $(\mathrm{hv}=1486.6 \mathrm{eV})$ operating at $10 \mathrm{kV}$ and $15 \mathrm{~mA}(150 \mathrm{~W})$. Wide energy survey scans (WESS) were recorded at a pass energy of $160 \mathrm{eV}$. High resolution spectra for $\mathrm{C} 1 \mathrm{~s}, \mathrm{O} 1 \mathrm{~s}, \mathrm{Ca} 2 \mathrm{p}$, $\mathrm{P} 2 \mathrm{p} / \mathrm{Sr} 3 \mathrm{~d}, \mathrm{Sr} 3 \mathrm{p}$ and $\mathrm{P} 2 \mathrm{~s}$ were recorded at pass energy of $40 \mathrm{eV}$. A Kratos charge neutraliser system was used for all samples. Sample charging effects on the calculated binding energy (BE) positions were adjusted by setting the lowest BE component of the $\mathrm{C} 1 \mathrm{~s}$ spectral envelope to $285.0 \mathrm{eV}$. 
Photoelectron spectra were further processed by subtracting a Tougaard background and using the peak area for the most intense spectral line of each detected elemental species to determine the atomic\%. In the case of the Sr-substituted samples, the P2p and Sr3d peaks overlap at 133/134 eV therefore, for these samples the P2s and Sr3p peaks were used in order to provide the appropriate quantification results. In total 3 areas were analysed from each sample.

Scanning electron microscopy (SEM) with energy dispersive X-ray (EDX) analysis was performed using a Hitachi SU5000 field emission instrument equipped with an X-Max ${ }^{\mathrm{N}} 80 \mathrm{~mm}^{2}$ silicon drift detector (Oxford Instruments, UK). For SEM and EDX analysis, an accelerating voltage of $10 \mathrm{kV}$ was used. To make the surface of the samples conductive for the electron microscopy, they were coated with a thin layer $(20 \mathrm{~nm})$ of $\mathrm{Au} / \mathrm{Pd}$ (60/40 ratio). The coating was performed using an Emitech K500X sputtering deposition with Argon gas.

Fourier transform infrared (FTIR) spectra were recorded using spectrometer (Varian 800 FT-IR, Scimitar Series, USA) in attenuated total reflectance (ATR, GladiATR ${ }^{\mathrm{TM}}$, Pike technologies, USA) mode. The FTIR spectra were obtained at $4 \mathrm{~cm}^{-1}$ resolution co-adding 50 scans over a range of wavenumbers from $400 \mathrm{~cm}^{-1}$ to $4000 \mathrm{~cm}^{-1}$. Before every measurement a background spectrum was taken (50 scans) and deducted from the sample spectrum.

X-Ray diffraction (XRD) analysis were performed using system (X'Pert PRO, PANalytical, the Netherlands) operating at $40 \mathrm{KV}$ and $30 \mathrm{~mA}$ using a $\mathrm{Cu} \mathrm{K} \alpha_{1}$ radiation $(\lambda=1.5406 \AA)$. Patterns were obtained over the range of 2-Theta from $10^{\circ}$ to $70^{\circ}$ with an angular step interval of $0.0334^{\circ}$. The X'Pert Data Viewer and X'Pert HighScore software were used for processing and analyzing the XRD data. For the phase identification the International Centre for Diffraction Data (ICDD) was used (PDF-2/2005 card \#01-072-1243 for HAp). Computer structural analysis of XRD diffractograms was performed by the Rietveld method using the software Profex-BGMN-Bundle- 
3.8.0 [22]. Rietveld's refinement for HAp was done based on data from with the hexagonal space group P63/m using PDF card \#01-074-0565 as structural model for HAp. $R_{w p}, R_{\exp }$ and $X^{2}$ for refinements indicate the quality of the fits. The observed, calculated and differential patterns are shown in Figure 2.
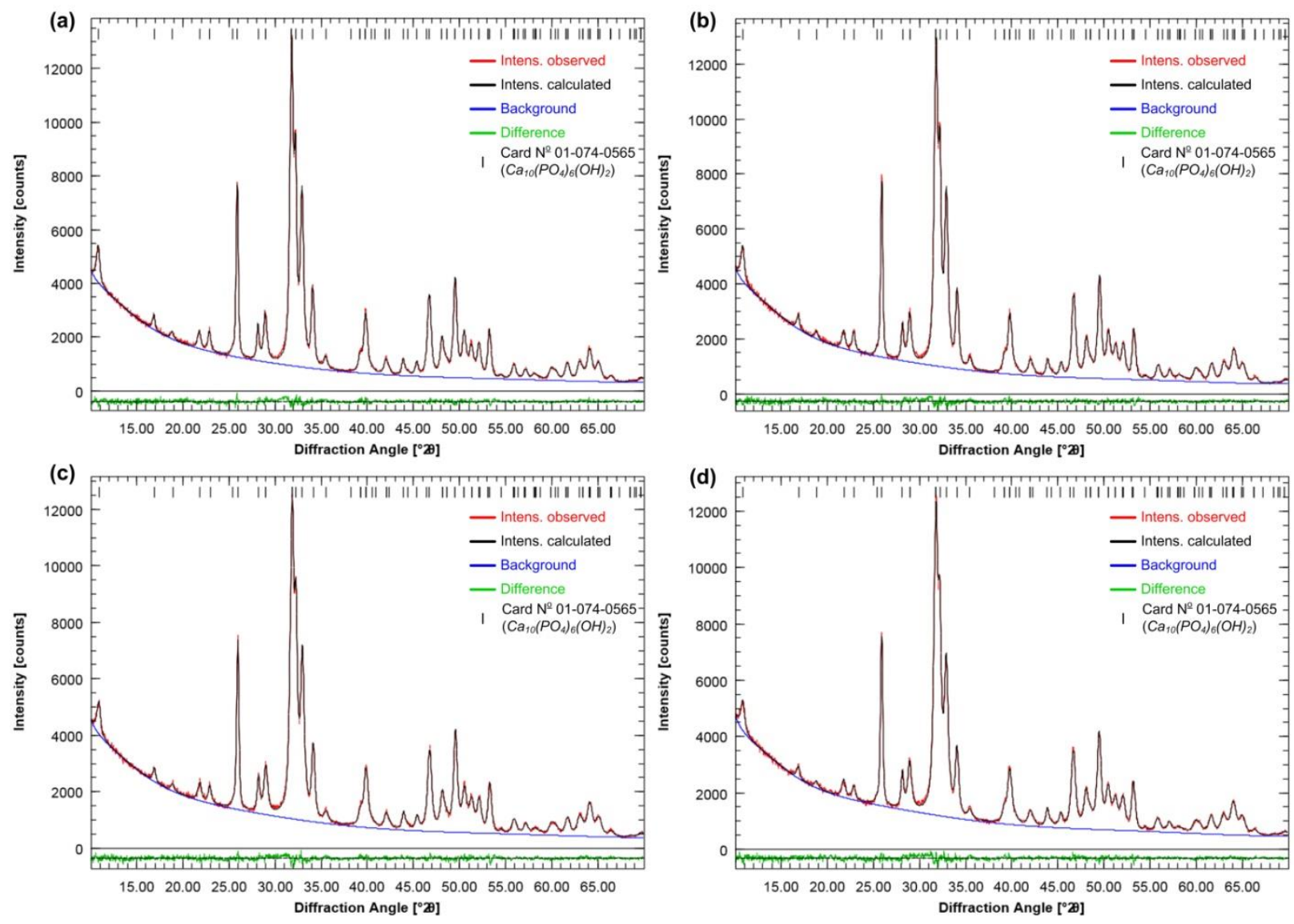

Figure 2. Observed (red), calculated (black) and differential (green) patterns for (a) HAp, (b) 2SrHAp, (c) 5SrHAp and (d) 10SrHAp calcined at $600{ }^{\circ} \mathrm{C}$ for $2 \mathrm{~h}$.

Transmission electron microscopy (TEM) observations were made using a JEOL 2100F microscope operating at $200 \mathrm{kV}$ bias voltage. The samples for TEM analysis were prepared by roughly grinding the sintered disks followed by sonication in ethanol. The sonicated solutions were drop-casted on a $\mathrm{Cu}$ grid with $3 \mathrm{~nm}$ carbon films and the images were recorded using a charged 
coupled device detector. Scanning transmission electron microscopy-energy dispersive X-ray analysis (STEM-EDX) was performed using Oxford instruments X-Max detector coupled with the same JOEL 2100F system at $1.5 \mathrm{~nm}$ spot size. The STEM images were recorded using a JEOL high-angle annular dark field (HAADF) detector. ImageJ software was utilised to measure the dimensions of 60 nanocrystals from each sample. The results are reported as the mean \pm standard deviation (SD).

\subsection{In vitro cell studies}

\subsubsection{Cytoskeletal and collagen I}

Primary human osteoblast cells (HOBC) were isolated and characterised using previously described method [23]. The SrHAp and HAp control samples were seeded with $2 \times 10^{5}$ cells/well in $1 \mathrm{~mL}$ medium (Dulbecco's modified eagle medium (DMEM) $+5 \%$ fetal calf serum (FCS), Sigma-Aldrich, UK) for 1,7 and 28 days. Fresh medium was added twice a week. At the predesignated time points (1,7 and 28 days), the cell culture supernatant was removed from the wells and samples were gently washed once with phosphate-buffered saline (PBS) without $\mathrm{Ca}^{2+}$ and $\mathrm{Mg}^{2+}$ at room temperature. Samples were then fixed with $4 \%$ formaldehyde, $2 \%$ sucrose solution in PBS and incubated for $15 \mathrm{~min}$ at $37^{\circ} \mathrm{C}, 5 \% \mathrm{CO}_{2}$ followed by further washing. Fixed samples were permeabilized with $0.05 \%$ Triton X100 solution (Sigma-Aldrich, UK) for $5 \mathrm{~min}$ at $4{ }^{\circ} \mathrm{C}$, followed by washing with PBS for $5 \mathrm{~min}$ at $37{ }^{\circ} \mathrm{C}$. Samples were incubated with the collagen I primary antibody (1:500 dilution with 1\% bovine serum albumin (BSA):PBS, Sigma-Aldrich, UK) overnight at $4{ }^{\circ} \mathrm{C}$, washed with $0.1 \%$ Tween 20 solution (ICN Biomedicals, USA) for 5 min at room temperature, followed by incubation with the Rhodamine conjugated goat IgG fraction to mouse IgG (Invitrogen, USA) secondary antibody at a concentration of $1 \mu \mathrm{g} / \mathrm{mL}$ in $1 \%$ BSA:PBS for $1 \mathrm{~h}$ at $37^{\circ} \mathrm{C}$. The samples were washed with Tween 20 wash solution and incubated with 
$5 \mu \mathrm{g} / \mathrm{mL}$ Oregon-green phalloidin (Molecular Probes, USA) for $30 \mathrm{~min}$ at $4{ }^{\circ} \mathrm{C}$. The samples were then placed onto glass slides and mounted with a fluorescence stabilising mounting medium with DAPI (Vectashield, Vector Laboratories Inc., UK). The samples were viewed immediately by confocal laser scanning microscopy (Zeiss 510, UK).

\subsubsection{Alkaline phosphatase enzymatic activity assay}

At each experimental endpoint (1, 7 and 28 days), the supernatant was removed from the wells. The cells were washed twice in ice-cold PBS and lysed in $0.1 \%$ Triton-X. $100 \mu \mathrm{L}$ of the lysate was transferred to a 96-well plate, $100 \mu \mathrm{L}$ of para-Nitrophenylphosphate (p-NPP) solution was added to the sample, allowed the reaction to take place at $37^{\circ} \mathrm{C}$ for $40 \mathrm{~min}$, and then $50 \mu \mathrm{L}$ of $3 \mathrm{M} \mathrm{NaOH}$ was added to terminate the reaction. The absorbance at $405 \mathrm{nM}$ within 15 min of terminating the reaction was read. The values obtained were normalized to the control measurements and expressed as a percentage of change from control, i.e., alkaline phosphatase (ALP) activity on the HAp samples at day 1. Results are expressed as an average value of the three assessments per series of samples $\pm \mathrm{SD}$. The differences were tested for statistical significance using a one-way ANOVA followed by Tukey post hoc test for multiple comparisons.

\section{Results}

\subsection{Physico-chemical characterization}

The chemical composition of all the samples was determined using AAS, EDX and XPS. The nominal and experimental amounts of Sr measured by AAS were close to the nominal values (Table 1). This indicates that no significant Sr losses have occurred during the synthesis. EDX of the pressed HAp disk gave a stoichiometry of $1.67 \pm 0.02$, equivalent to that of pure HAp. The 
corresponding $\mathrm{Ca} / \mathrm{P}$ ratios of the $\mathrm{Sr}$-substituted HAp materials were higher than expected, with values reported between $1.74 \pm 0.01$ and $1.76 \pm 0.02$, as shown in Table 2 and Figure 3. The corresponding $(\mathrm{Ca}+\mathrm{Sr}) / \mathrm{P}$ ratios were shown to be slightly higher than the $\mathrm{Ca} / \mathrm{P}$ ratio, with the $\mathrm{Sr} /(\mathrm{Ca}+\mathrm{Sr})$ atomic ratios increasing with the increasing levels of $\mathrm{Sr}$ in the samples. The additional EDX peaks correspond to either $\mathrm{Au} / \mathrm{Pd}$ coating or adventitious carbon on the surface of the samples (with peaks at $0.28 \mathrm{KeV}\left(\mathrm{C} \mathrm{K}_{\alpha}\right), 2.12 \mathrm{keV}\left(\mathrm{Au} \mathrm{M}_{\alpha}\right)$ and $2.83 \mathrm{keV}\left(\mathrm{Pd} \mathrm{L}_{\alpha}\right)$ ). No other impurities were detected from the EDX analysis.

Table 1. Nominal and AAS quantification results from the powders calcined at $600{ }^{\circ} \mathrm{C}$ for $2 \mathrm{~h}$.

\begin{tabular}{c|c|c|c|c|c|c|c|c}
\hline \multirow{2}{*}{ Sample } & \multicolumn{2}{|c|}{$\begin{array}{c}\text { Nominal Sr } \\
\text { content }\end{array}$} & \multicolumn{2}{c|}{$\begin{array}{c}\text { Experimental Sr } \\
\text { content } \\
\text { (by AAS) }\end{array}$} & \multicolumn{2}{c|}{$\begin{array}{c}\text { Nominal } \\
\text { Sr/(Ca + Sr) }\end{array}$} & \multicolumn{2}{c}{$\begin{array}{c}\text { Experimental } \\
\text { Sr/(Ca + Sr) }\end{array}$} \\
\cline { 2 - 9 } & wt\% & at\% & wt\% & at\% & $\begin{array}{c}\text { atomic } \\
\text { ratio }\end{array}$ & $\begin{array}{c}\text { weight } \\
\text { ratio }\end{array}$ & $\begin{array}{c}\text { atomic } \\
\text { ratio }\end{array}$ & $\begin{array}{c}\text { weight } \\
\text { ratio }\end{array}$ \\
\hline HAp & - & - & - & - & - & - & - & - \\
\hline 2SrHAp & 0.78 & 9.00 & $0.56 \pm 0.06$ & $6.44 \pm 0.69$ & 0.01 & 0.02 & $0.01 \pm 0.00$ & $0.01 \pm 0.00$ \\
\hline 5SrHAp & 2.07 & 24.00 & $1.41 \pm 0.14$ & $16.29 \pm 1.62$ & 0.02 & 0.05 & $0.02 \pm 0.01$ & $0.04 \pm 0.01$ \\
\hline 10SrHAp & 4.09 & 48.00 & $3.10 \pm 0.30$ & $36.15 \pm 3.50$ & 0.05 & 0.10 & $0.04 \pm 0.01$ & $0.08 \pm 0.01$ \\
\hline
\end{tabular}

Table 2. EDX quantification results from the surfaces of the discs sintered at $600{ }^{\circ} \mathrm{C}$ for $2 \mathrm{~h}$.

\begin{tabular}{c|c|c|c}
\hline Sample & $\mathbf{C a} / \mathbf{P}$ & $\mathbf{( C a + S r ) / P}$ & $\mathbf{S r} /(\mathbf{C a}+\mathbf{S r})$ \\
\hline HAp & $1.67 \pm 0.02$ & $1.67 \pm 0.02$ & - \\
\hline 2SrHAp & $1.75 \pm 0.02$ & $1.77 \pm 0.02$ & $0.01 \pm 0.01$ \\
\hline 5SrHAp & $1.76 \pm 0.02$ & $1.81 \pm 0.03$ & $0.02 \pm 0.01$ \\
\hline 10SrHAp & $1.74 \pm 0.01$ & $1.81 \pm 0.01$ & $0.04 \pm 0.01$ \\
\hline
\end{tabular}




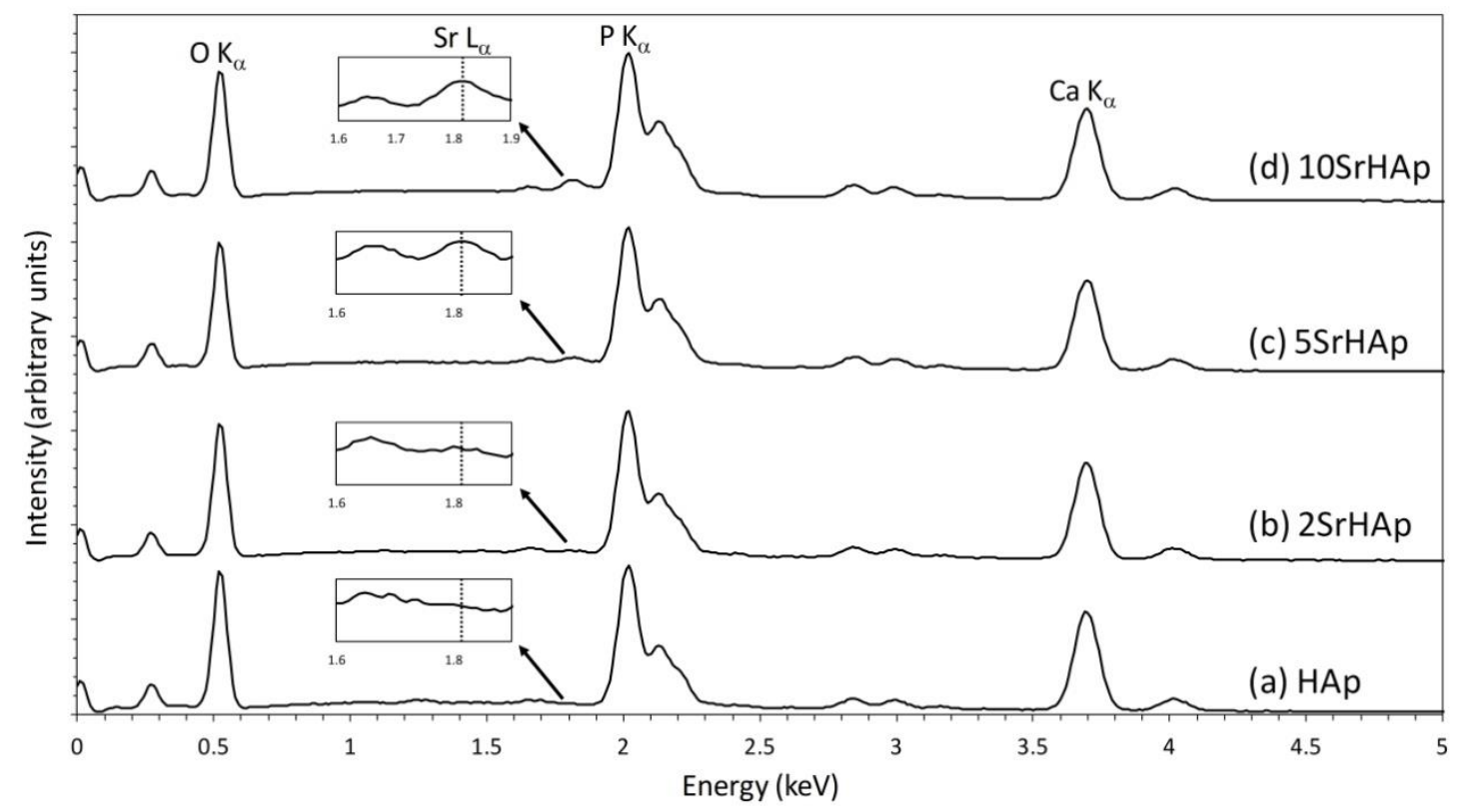

Figure 3. EDX spectra for (a) HAp, (b) 2SrHAp, (c) 5SrHAp, (d) 10SrHAp discs sintered at 600 ${ }^{\circ} \mathrm{C}$ for $2 \mathrm{~h}$.

Figure 4 show typical XPS WESS for (a) HAp and (b) 10SrHAp. For the HAp sample, all the expected peaks for O1s, C1s Ca2p, P2p and P2s were detected, as shown in Table 4. However, the $\mathrm{Ca} / \mathrm{P}$ ratio was slightly lower than the expected 1.67 for stoichiometric $\mathrm{HAp}$, at $1.60 \pm 0.03$ as highlighted in Table 3. For all three Sr-substituted samples, the WESS showed the presence of Sr, as evidenced by the $\mathrm{Sr} 3 \mathrm{p}_{3 / 2}$ peak around $269.0 \mathrm{eV}$ (Table 4 and Figures 4(b) for the 10SrHAp sample). The corresponding high resolution $\mathrm{Sr}_{3} \mathrm{p}_{3 / 2}$ peaks, as shown in Figures 5(d, g and $\mathrm{j}$ ) for 2SrHAp, 5SrHAp and 10SrHAp, respectively, confirm the presence and successful substitution of

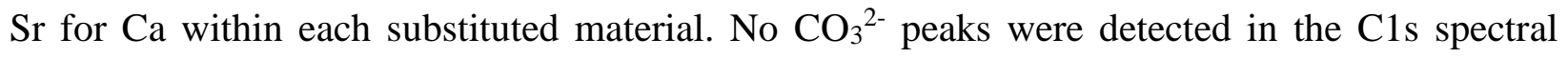
envelope (typically observed around 289.0-290.0 eV) [24]. The Ca/P ratios for the $\mathrm{Sr}$-substituted samples were calculated at $1.44 \pm 0.07$ for $2 \mathrm{SrHAp}, 1.41 \pm 0.05$ for $5 \mathrm{SrHAp}$ and $1.29 \pm 0.06$ for 10SrHAp (as shown in Table 3), all of which are lower than 1.67 for stoichiometric HAp. As all 
three Sr-substituted samples contain Sr (as determined by AAS, EDX and XPS), it should be noted that the spectral envelope observed around 133.4-133.8 eV comprises an overlap of the Sr3d and $\mathrm{P} 2 \mathrm{p}$ peaks as the $\mathrm{Sr} 3 \mathrm{~d}_{5 / 2}(133 \pm 0.5 \mathrm{eV}), \mathrm{Sr} 3 \mathrm{~d}_{3 / 2}(135 \pm 0.5 \mathrm{eV})$ and the $\mathrm{P} 2 \mathrm{p}(132-133 \mathrm{eV})$ lines are positioned very close together. Therefore, in order to quantify the $\mathrm{P}$ and $\mathrm{Sr}$ at\% values in the $\mathrm{Sr}$ substituted samples, the P2s and Sr3p peaks are used instead of the P2p and Sr3d peaks. The main peaks recorded for all Sr-substituted samples shown in Table 4 were therefore Ca2p $\mathrm{p}_{3 / 2}$ (347.5$347.7 \mathrm{eV}), \mathrm{P} 2 \mathrm{~s}(190.9-190.2 \mathrm{eV}), \mathrm{O} 1 \mathrm{~s}(530.4 \mathrm{eV})$ and Sr3p $3 / 2(269.2-269.7 \mathrm{eV})$.

The $(\mathrm{Ca}+\mathrm{Sr}) / \mathrm{P}$ ratios for each $\mathrm{Sr}$-substituted sample determined by XPS (see Table 3), are as follows: $1.45 \pm 0.07$ for 2 SrHAp, $1.43 \pm 0.05$ for 5 SrHAp and $1.35 \pm 0.06$ for 10SrHAp. EDX analyse approximately $1 \mu \mathrm{m}$ depth of the disk samples, whereas XPS only analyse the top 5-10 $\mathrm{nm}$ of the disks sample surface [25]. There is a high probability that the total area of analysis in XPS and EDS is different which gives rise to the difference in $\mathrm{Ca} / \mathrm{P}$ and $(\mathrm{Ca}+\mathrm{Sr}) / \mathrm{P}$ ratios observed. However, it can be seen that for each sample the ratio is slightly larger for $(\mathrm{Ca}+\mathrm{Sr}) / \mathrm{P}$ in comparison to the $\mathrm{Ca} / \mathrm{P}$ ratios alone, highlighting that for each $\mathrm{Sr}$-substituted sample $\mathrm{Sr}$ has been successfully substituted for $\mathrm{Ca}$ within HAp. The corresponding $\mathrm{Sr} /(\mathrm{Ca}+\mathrm{Sr})$ ratios found in Table 3 are interesting as they show a clear increase in Sr substitution, therefore, $0.01 \pm 0.00$ for 2SrHAp, 0.02 \pm 0.01 for $5 \mathrm{SrHAp}$, and $0.04 \pm 0.01$ for $10 \mathrm{SrHAp}$. This data indicates that as the amount of $\mathrm{Sr}$ is increased in the following sequence $2 \mathrm{SrHAp} \rightarrow 5 \mathrm{SrHAp} \rightarrow 10 \mathrm{SrHAp}$ as highlighted by AAS in Table 1 for each Sr-substituted samples, the subsequent percentage ratios of atomic concentration also increase accordingly, confirming that as a larger percentage concentration of $\mathrm{Sr}$ is added at the beginning of the reaction, a larger amount of $\mathrm{Sr}$ is substituted for Ca within the SrHAp sample. It should be noted that the $\mathrm{Sr} /(\mathrm{Ca}+\mathrm{Sr})$ values as determined by XPS correlate strongly with the $\mathrm{Sr} /(\mathrm{Ca}+\mathrm{Sr})$ results from the AAS and the EDX, as shown in Table 1 (AAS), Table 2 (EDX) and 
Table 3 (XPS). No impurities were detected from the XPS analysis. This suggests that the aqueous precipitation synthesis employed here successfully substitutes $\mathrm{Sr}$ within the HAp lattice as amounts of the Sr source are increased.
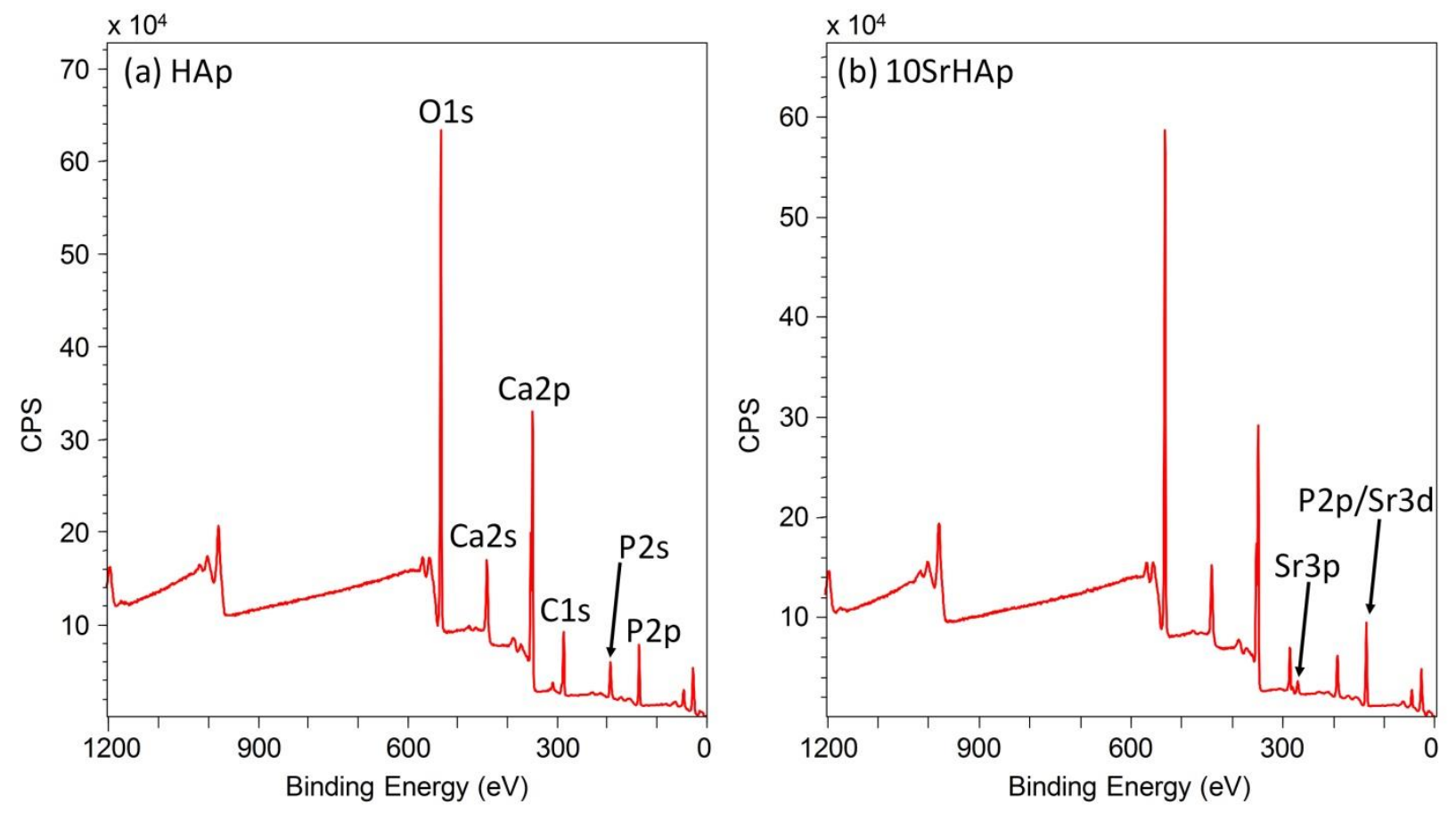

Figure 4. XPS WESS of (a) HAp and (b) 10SrHAp discs sintered at $600{ }^{\circ} \mathrm{C}$ for $2 \mathrm{~h}$. 

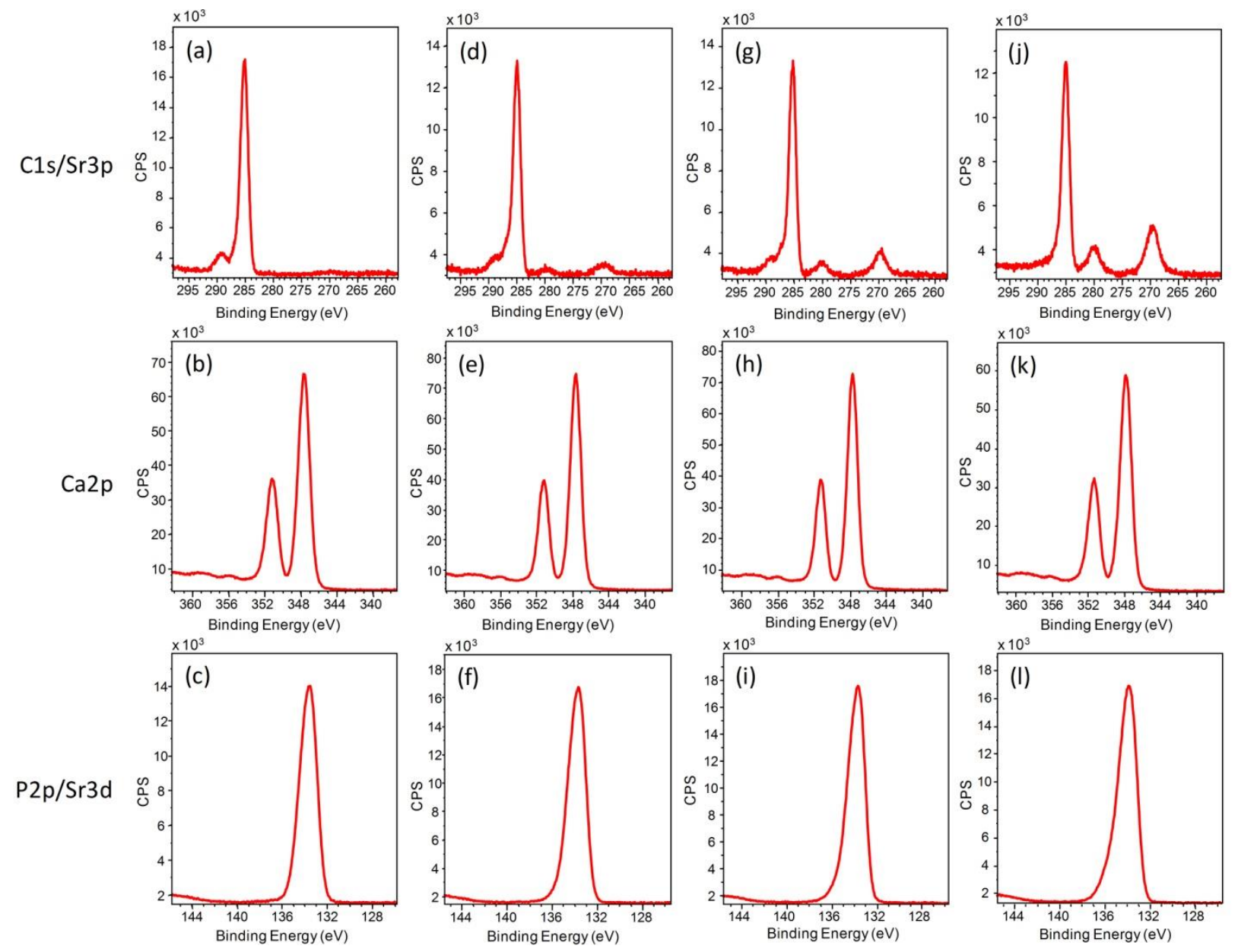

Figure 5. XPS of (a-c) HAp, (d-f) 2SrHAp, (g-i) 5SrHAp, (j-1) 10SrHAp discs sintered at $600{ }^{\circ} \mathrm{C}$ for $2 \mathrm{~h}$.

Table 3. XPS quantification results from the surface of the discs sintered at $600{ }^{\circ} \mathrm{C}$ for $2 \mathrm{~h}$.

\begin{tabular}{c|c|c|c}
\hline Sample & $\mathbf{C a} / \mathbf{P}$ & $(\mathbf{C a}+\mathbf{S r}) / \mathbf{P}$ & $\mathbf{S r} /(\mathbf{C a}+\mathbf{S r})$ \\
\hline HAp & $1.60 \pm 0.03$ & - & - \\
\hline 2SrHAp & $1.44 \pm 0.07$ & $1.45 \pm 0.07$ & $0.01 \pm 0.00$ \\
\hline 5SrHAp & $1.41 \pm 0.05$ & $1.43 \pm 0.05$ & $0.02 \pm 0.01$ \\
\hline 10SrHAp & $1.29 \pm 0.06$ & $1.35 \pm 0.06$ & $0.04 \pm 0.01$ \\
\hline
\end{tabular}

Table 4. Peak positions (eV) as determined by XPS.

\begin{tabular}{c|c|c|c|c|c|c}
\hline \multirow{2}{*}{ Sample } & \multicolumn{6}{|c}{ Peak Positions - BE (eV) } \\
\cline { 2 - 7 } & C1s & O1s & Ca2p3/2 & P2p/Sr3d5/2 & P2s & Sr3p3/2 \\
\hline HAp & 285.0 & 531.4 & 347.5 & 133.4 & 190.9 & - \\
\hline
\end{tabular}




\begin{tabular}{c|c|c|c|c|c|c}
\hline 2SrHAp & 285.0 & 531.4 & 347.5 & 132.8 & 190.9 & 269.3 \\
\hline 5SrHAp & 285.0 & 531.4 & 347.5 & 133.7 & 191.0 & 269.7 \\
\hline 10SrHAp & 285.0 & 531.4 & 347.7 & 133.8 & 191.2 & 269.2 \\
\hline
\end{tabular}

A typical FTIR spectrum for SrHAp is shown in Figure 6 with absorbance bands at 1090, 1022, 963, 560, 600 and $472 \mathrm{~cm}^{-1}$ attributed to phosphate [PO 4$]$ vibrations and at 3569 and 631 $\mathrm{cm}^{-1}$ attributed to characteristic $[\mathrm{OH}]$ bands [26]. The only difference observed in the spectra was that with an increase of $\mathrm{Sr}$ content, the intensity of the $[\mathrm{OH}]$ groups' absorption band at $631 \mathrm{~cm}^{-1}$ decreased. This is in good agreement with previous studies suggesting that substituting $\mathrm{Ca}^{2+}$ ions with ionic radius $0.100 \mathrm{~nm}$ with larger $\mathrm{Sr}^{2+}$ ions with radius of $0.118 \mathrm{~nm}$ results in perturbation of

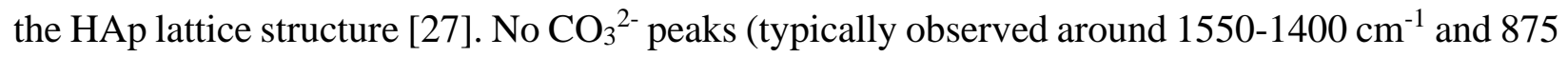
$\mathrm{cm}^{-1}$ ) were detected in any of the samples from the FTIR analyses [28].
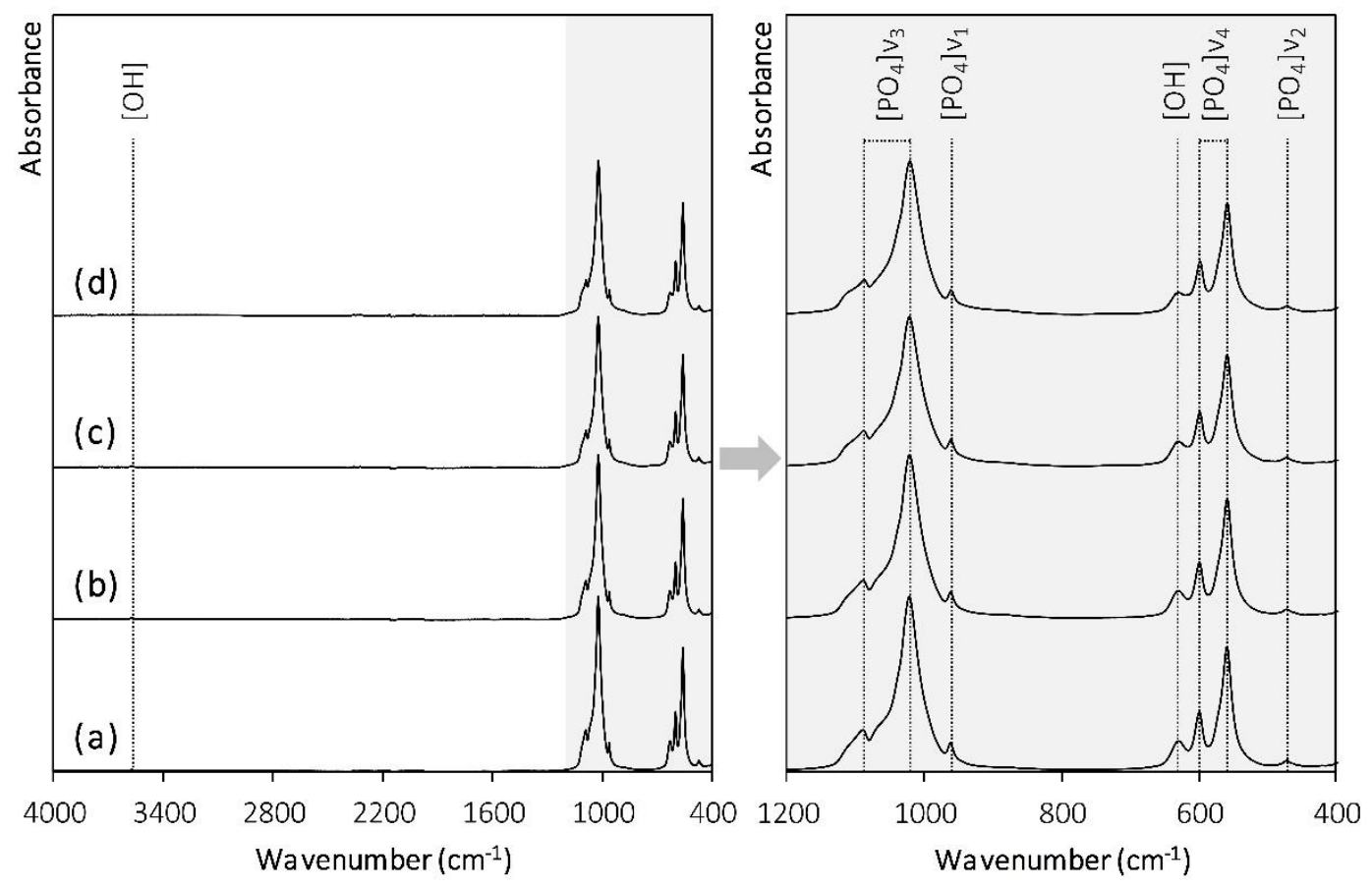

Figure 6. FTIR spectra of (a) HAp, (b) 2SrHAp, (c) 5 SrHAp, (d) 10SrHAp calcined at $600{ }^{\circ} \mathrm{C}$ for $2 \mathrm{~h}$. 
The XRD patterns shown in Figure 7 indicate that regardless of the chemical composition all samples had a hexagonal lattice structure with space group P6/m typical to HAp [29]. Displacement of the peaks, which according to analogous studies would confirm the incorporation of Sr into the HAp structure [30], was observed for all the Sr substituted materials (Table 5). At the same time, peaks indicating the presence of other Sr-containing compounds were not detected. Slight broadening and merging of peaks as $\mathrm{Sr}$ content increases was observed, specifically, for peaks (211) and (112). The full width half maximum (FWHM) for the representative peaks are shown in Table 6. This is consistent with studies reporting that incorporation of $\mathrm{Sr}$ causes deformation of the HAp crystalline structure, which leads to a decrease in crystallinity [31]. The broadening of the peaks can also be a consequence of nano-sized crystals, i.e. reduction of the crystallite size [32]. Although the broadening and shift in the peak positions are very small, they are very consistent with the amount of $\mathrm{Sr}$.

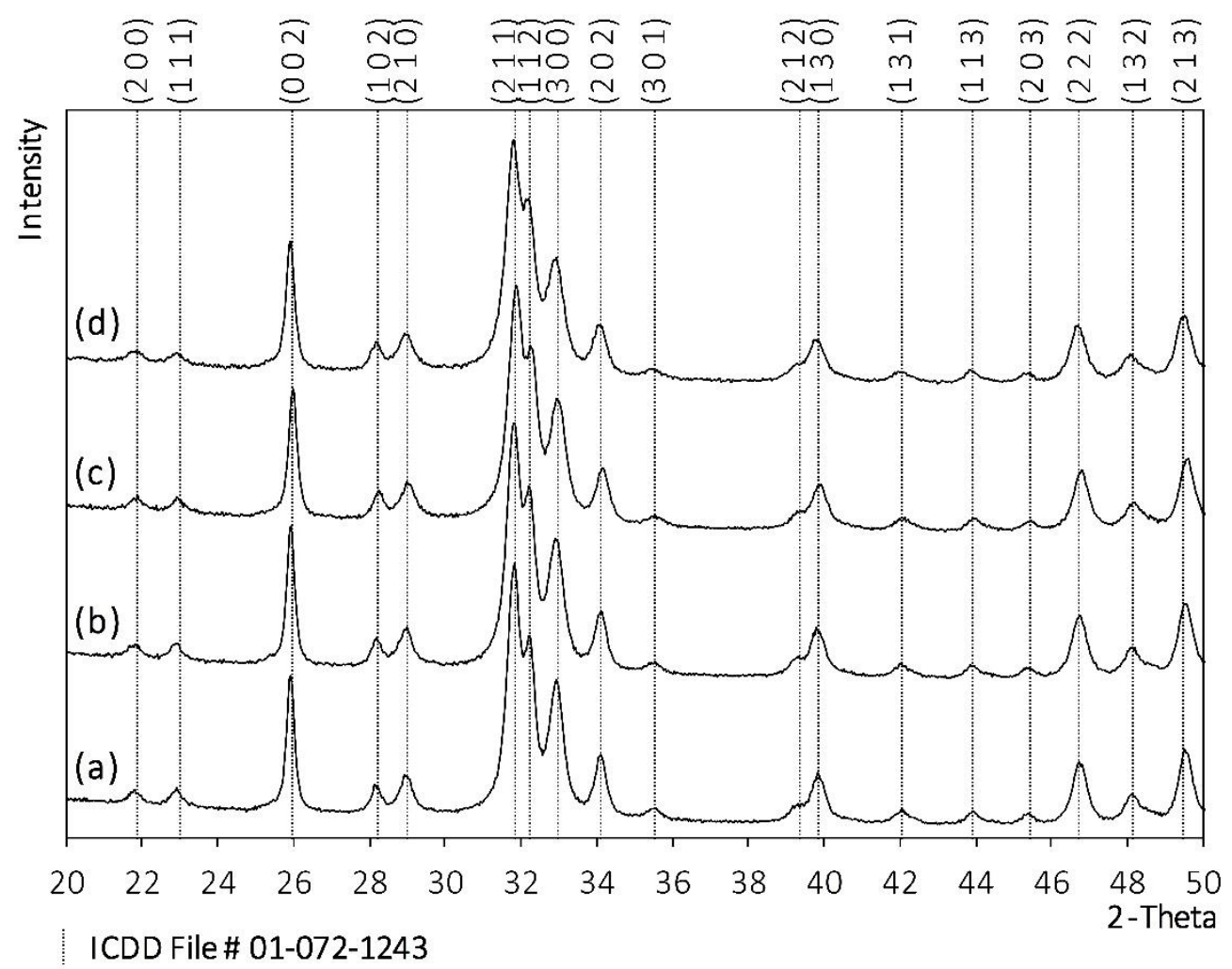


Figure 7. XRD patterns of (a) HAp, (b) 2SrHAp, (c) 5SrHAp, (d) 10SrHAp calcined at $600{ }^{\circ} \mathrm{C}$ for $2 \mathrm{~h}$.

Table 5. $2 \theta$ Position (degrees) values for the peaks of various samples.

\begin{tabular}{c|c|c|c|c}
\hline Plane & HAp & 2SrHAp & 5SrHAp & 10SrHAp \\
\hline$(002)$ & 25.8961 & 25.8938 & 25.8839 & 25.8615 \\
\hline$(211)$ & 31.7668 & 31.7560 & 31.7530 & 31.7323 \\
\hline$(130)$ & 39.7873 & 39.7727 & 39.7520 & 39.7296 \\
\hline$(222)$ & 46.7074 & 46.6946 & 46.6795 & 46.6298 \\
\hline
\end{tabular}

Table 6. FWHM (in degrees) values for the peaks of various samples as determined from the

TEM analyses.

\begin{tabular}{c|c|c|c|c|c}
\hline Plane & 2ө (degrees) & HAp & 2SrHAp & 5SrHAp & 10SrHAp \\
\hline$(002)$ & 25.8 & 0.2446 & 0.2540 & 0.2602 & 0.2660 \\
\hline$(211)$ & 31.7 & 0.4698 & 0.5045 & 0.5527 & 0.5739 \\
\hline$(130)$ & 39.7 & 0.5014 & 0.5393 & 0.5944 & 0.6021 \\
\hline$(222)$ & 46.7 & 0.4342 & 0.4435 & 0.4522 & 0.4634 \\
\hline
\end{tabular}

The above observations regarding changes in crystallite size with increasing $\mathrm{Sr}$ content were confirmed by Rietveld analysis. Refined lattice parameters, crystallite size and $R$-values obtained for all samples are listed in Table 7. The low $R$-values confirm the successful and reliable performed refinements. The $c$ and $a$ axis parameters values show little effect with the different $\mathrm{Sr}$ content, i.e. slightly increases with increasing $\mathrm{Sr}$ content suggesting the larger radius ions entered the apatite lattice and induced the hexagonal lattice expansion. This is in a good agreement with the results obtained by Chen et al. [33]. All the samples have larger crystallite size along the [001] plane compared to that along the [100] plane, irrespective of the Sr content. In general, the size of crystallites decreases by increasing the $\mathrm{Sr}$ content in the hexagonal HAp structure. 
Table 7. Lattice parameters and $R$-values for HAp and SrHAp samples obtained by Rietveld refinement.

\begin{tabular}{c|c|c|c|c|c}
\hline \multicolumn{2}{c|}{} & HAp & 2SrHAp & 5SrHAp & 10SrHAp \\
\hline \multirow{2}{*}{ Lattice parameters $(\AA)$} & $a$ & 9.42854 & 9.43273 & 9.43623 & 9.44355 \\
\cline { 2 - 6 } & $c$ & 6.88281 & 6.88329 & 6.88650 & 6.89267 \\
\hline \multirow{2}{*}{ Crystallite size (nm) } & {$[001]$} & $60.30 \pm 2.50$ & $61.60 \pm 2.70$ & $56.40 \pm 2.20$ & $56.20 \pm 2.50$ \\
\cline { 2 - 6 } & {$[100]$} & $24.64 \pm 0.37$ & $22.98 \pm 0.31$ & $21.88 \pm 0.28$ & $19.82 \pm 0.29$ \\
\hline \multirow{3}{*}{$\boldsymbol{R}$-Values (\%) } & $R_{\exp }(\%)$ & 2.44 & 2.38 & 2.36 & 2.27 \\
\cline { 2 - 6 } & $R_{w p}(\%)$ & 3.20 & 3.23 & 3.18 & 3.07 \\
\cline { 2 - 6 } & $X^{2}$ & 1.72 & 1.84 & 1.82 & 1.83 \\
\hline
\end{tabular}

The high-resolution TEM images shown in Figure 8 indicate that the average length of the HAp crystals is $106 \pm 23 \mathrm{~nm}$, with crystals measuring from 69 to $168 \mathrm{~nm}$. In comparison, the average length of the Sr-substituted materials is on the nanoscale, with values reported for the 2SrHAp of $82 \pm 22 \mathrm{~nm}$ (range of 44-157 nm), 5SrHAp of $67 \pm 16 \mathrm{~nm}$ (range of 32-115 nm) and 10SrHAp of $51 \pm 11 \mathrm{~nm}$ (range of 28-88 nm). This decrease in the dimensions of the measured crystals with increasing Sr content would be in line with expectations, as Sr substitution of HAp inhibits crystal growth [34]. This is in accordance with the XRD observations where the broadening increases with the increased levels of Sr substitution. Further to this, for all the Srsubstituted samples, larger flatter crystals of varying dimensions are observed (typically up to 300 $\mathrm{nm}$ in length), which are not seen in the HAp sample. The SEM micrographs of the surface of the HAp and SrHAp disks corroborated the results of the TEM, as shown in Figure 9. Two distinct morphologies were observed, with predominantly small rod-like features observed for the HAp, with larger flatter features clearly shown for the 2SrHAp, 5SrHAp and 10SrHAp disk sample surfaces, as shown in Figures 9(b-d), respectively. In addition, as the Sr content increased, the amount of the larger flatter particles increased. Based on analogous studies, this could indicate that 
non-miscible phases of Ca-rich HAp and Sr-rich HAp have formed [35], [36]. However, the indepth STEM-EDX (as shown in Figure 10) and TEM (Figure 11) analysis confirmed the presence of $\mathrm{Sr}$ in both the rod-like crystals and the larger flatter crystals. STEM-EDX mapping of the distribution of $\mathrm{Ca}, \mathrm{P}, \mathrm{O}$ and $\mathrm{Sr}$ highlighted that these elements were homogeneously distributed across both the rod-like and larger flatter crystals, as observed in Figure 10(a). As shown in Figure 10(b), the peak ratio of $\mathrm{Sr} / \mathrm{Ca}$ for both rod-shaped and flatter crystals were very similar indicating no major change in the Sr ratio in the two types of crystallites.
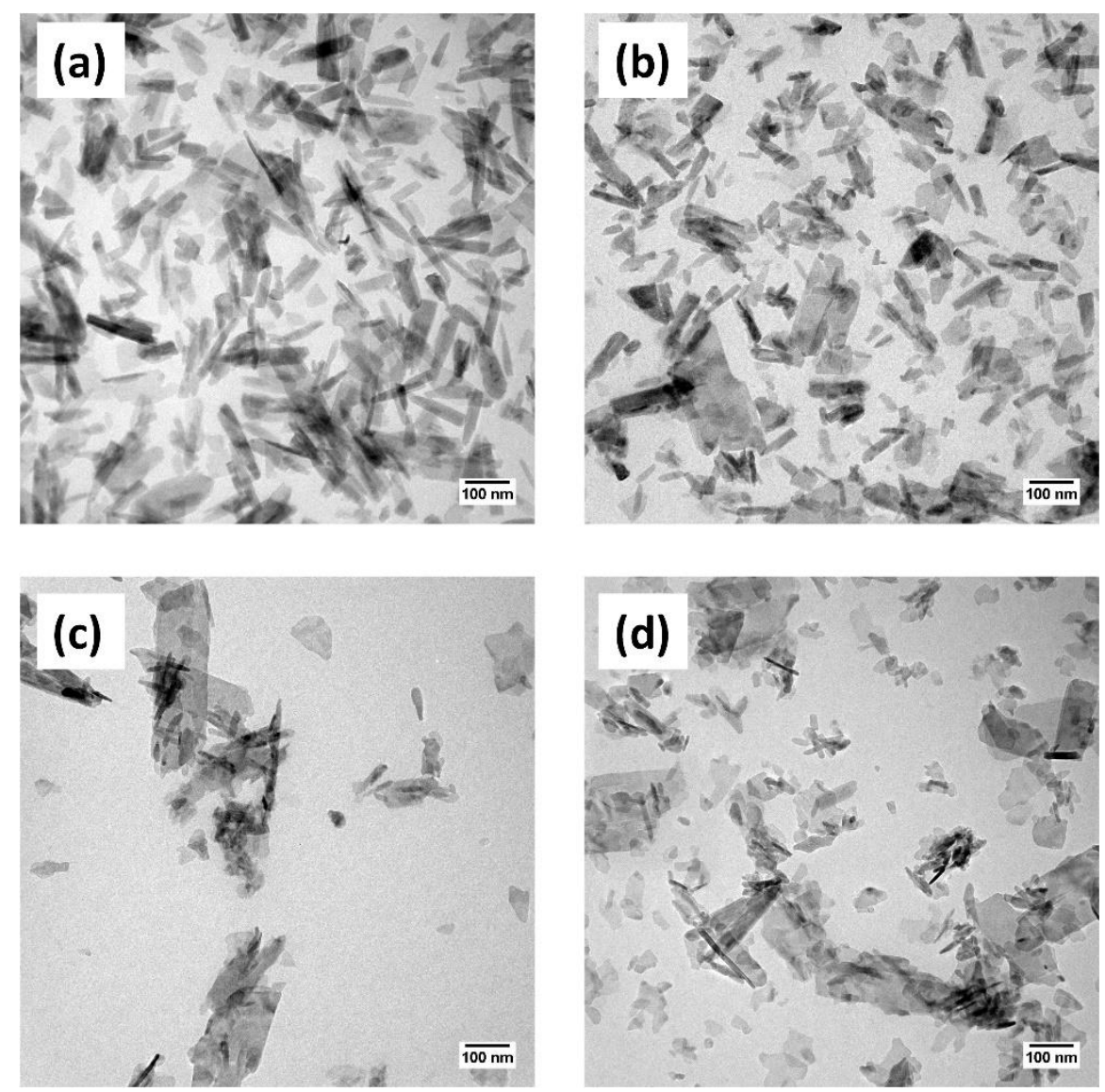

Figure 8. TEM micrographs of (a) HAp, (b) 2SrHAp, (c) 5SrHAp, (d) 10SrHAp calcined at 600 ${ }^{\circ} \mathrm{C}$ for $2 \mathrm{~h}$ (scale bar $100 \mathrm{~nm}$ ). 

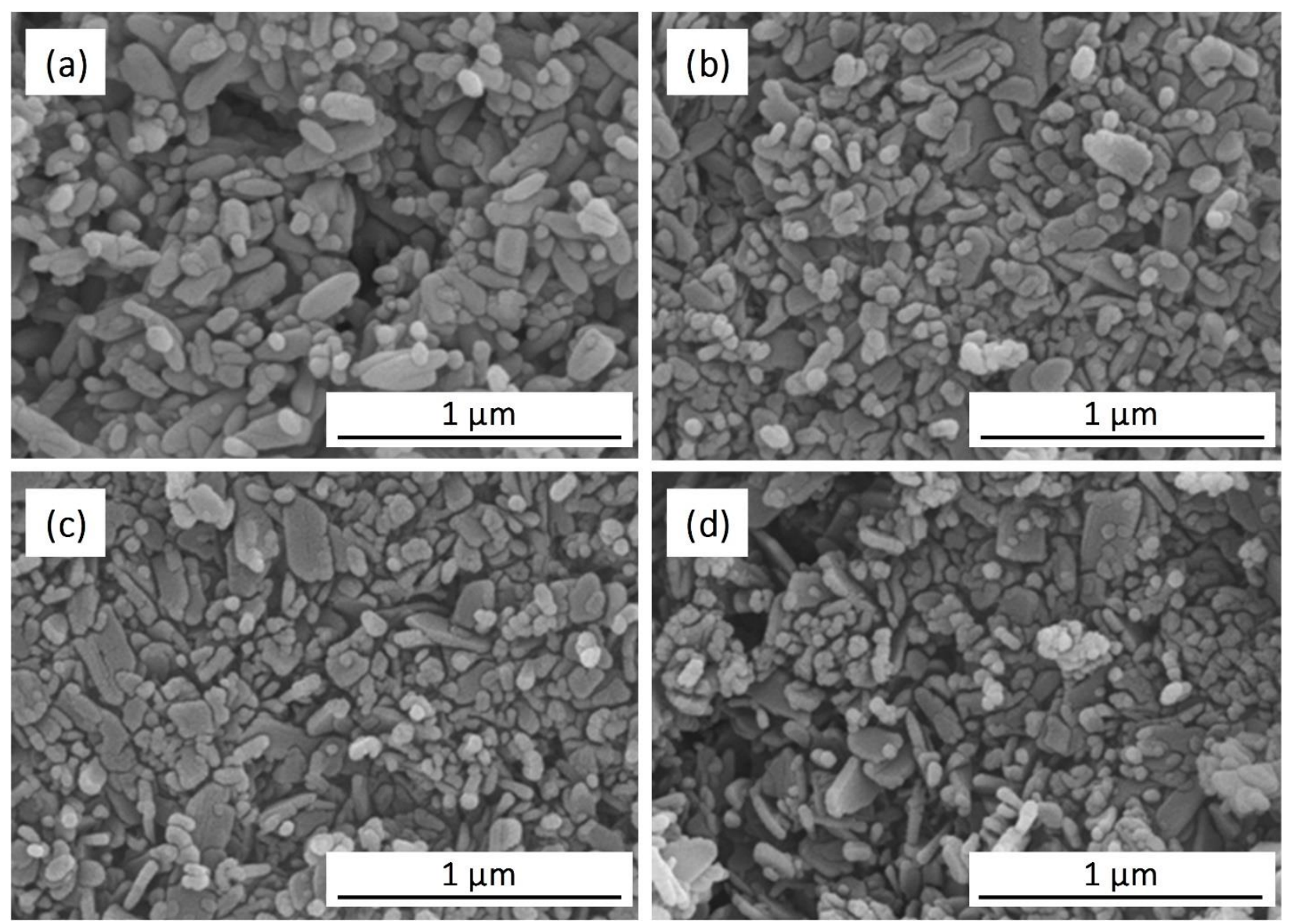

Figure 9. SEM surface micrographs of (a) HAp, (b) 2SrHAp, (c) 5SrHAp, (d) 10SrHAp discs sintered at $600{ }^{\circ} \mathrm{C}$ for $2 \mathrm{~h}$.

Further detailed analyses of the TEM results clearly highlights that for the SrHAp samples both the rod-like crystals and flatter larger crystals observed (as shown in Figure 11) have lattice spacings corresponding to the (002) plane of HAp. This indicates that the flat regions, although not observed in pure HAp samples, have maintained the native lattice structure even upon the substitution of $\mathrm{Ca}^{2+}$ with $\mathrm{Sr}^{2+}$. This concurs with the STEM-EDX observations highlighted in Figure 10. The selected area electron diffraction (SAED) patterns from the TEM analyses (Figure 12) show the different planes of the HAp and 10SrHAp samples, which correspond to those observed earlier in the XRD analyses (Figure 7). 

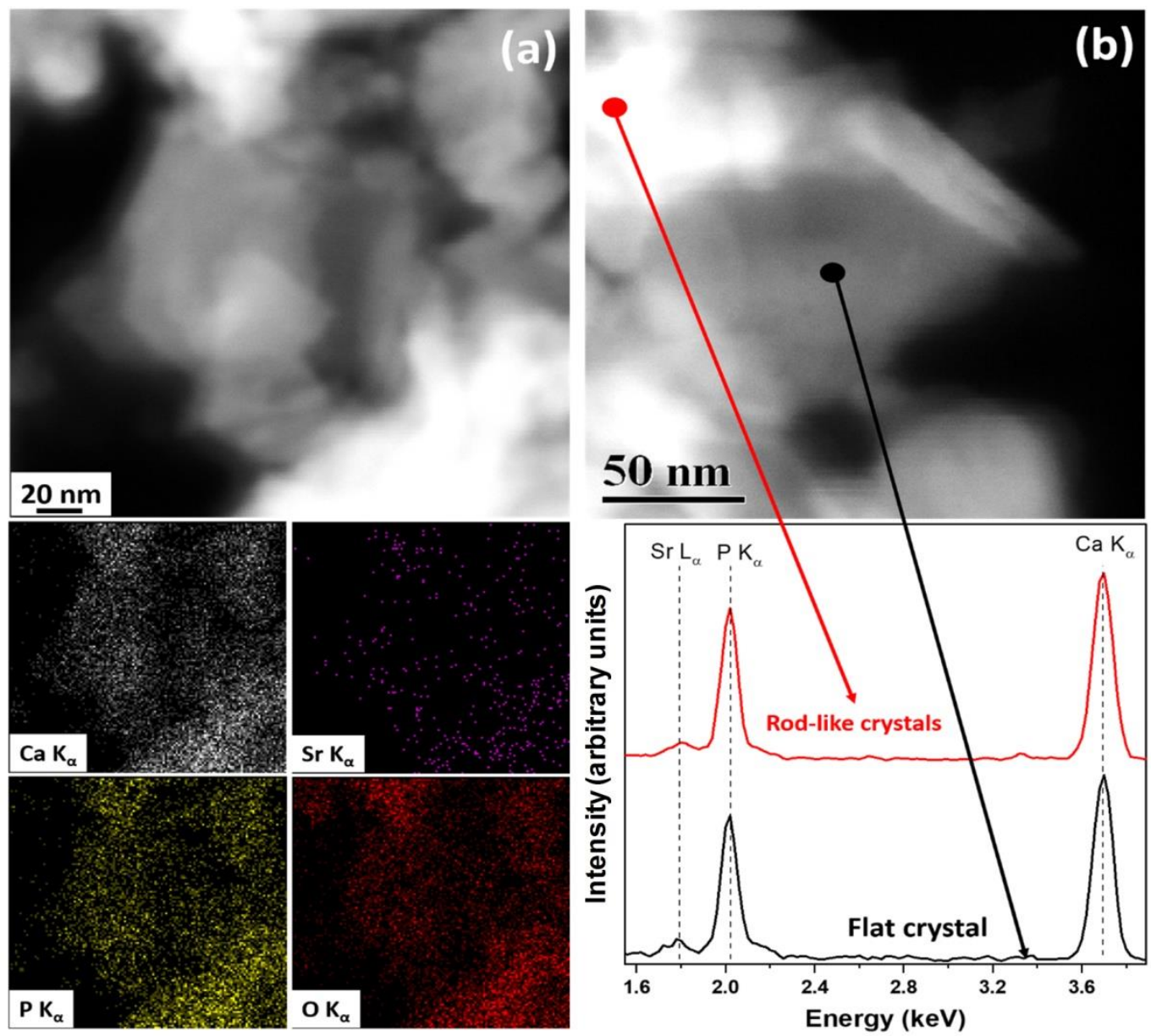

Figure 10. (a) STEM-EDX results of $10 \mathrm{SrHAp}$ calcined at $600{ }^{\circ} \mathrm{C}$ for $2 \mathrm{~h}$ showing the presence of $\mathrm{Sr}$ in both flat and rod-like crystals and (b) shows the EDX spectra from points on flatter and rod-like crystals. 

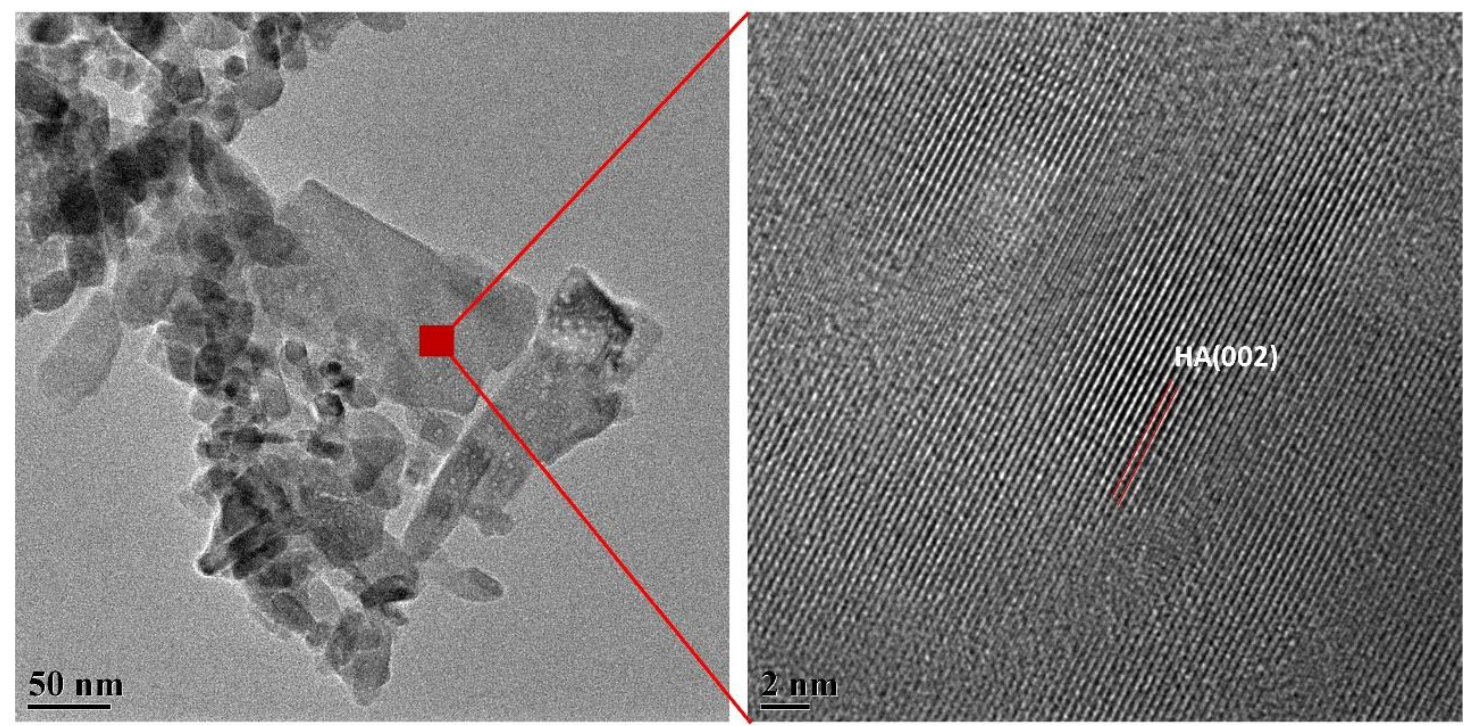

Figure 11. TEM image (left - scale bar $50 \mathrm{~nm}$ ) and corresponding high-resolution TEM image (right - scale bar $2 \mathrm{~nm}$ ) from 10SrHAp samples.

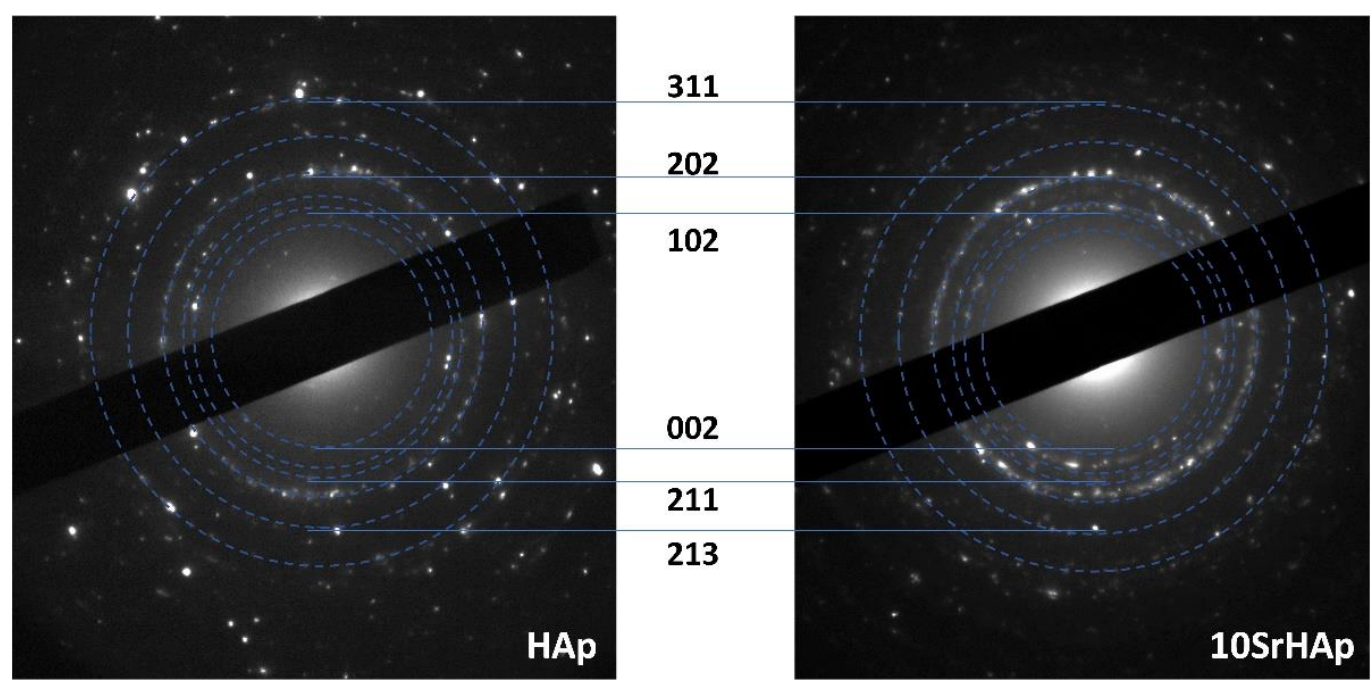

Figure 12. SAED pattern from (left) HAp and (right) 10SrHAp. The diffraction rings corresponding to various planes (miller indices) are highlighted in the centre of the Figure. 


\subsection{In vitro characterization}

Qualitative in vitro evaluation (Figure 13) showed that throughout the test period all SrHAp samples maintained viable cell adhesion throughout the 28-day test period and were positive for collagen I at day 1 , which increased by day 28 . The HAp control sample supported minimal viable cell adhesion and, viable cells were not observed by day 28 . In addition to positive collagen I staining, cells cultured in contact with the 2SrHAp, 5SrHAp and 10SrHAp materials demonstrated a high level of actin fibre organisation by day 28 and an enhanced expression of collagen I compared to earlier time points, with a denser and more organised expression observed for the 10SrHAp sample compared to other samples in the series (or HAp), as shown in Figure 13. Moreover, the reorganisation of the matrix as the osteoblast becomes an osteocyte is signalled by a reduction in ALP activity, which is clearly seen in Figure 14 [37]. 

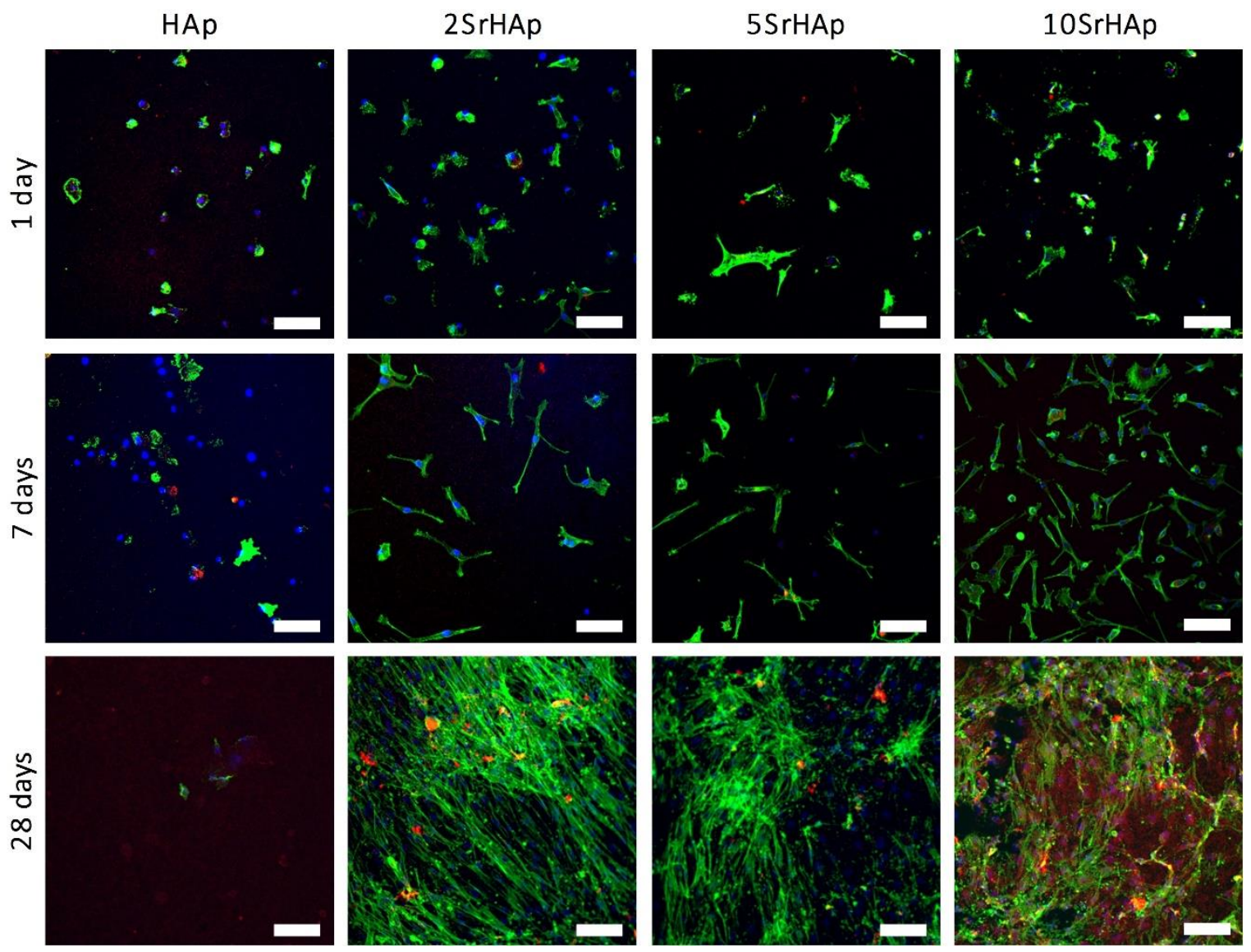

Figure 13. Qualitative immunohistochemistry for collagen I, when cells were cultured in contact with HAp, 2SrHAp, 5SrHAp and 10SrHAp discs sintered at $600{ }^{\circ} \mathrm{C}$ for $2 \mathrm{~h}$ (samples were stained with DAPI (blue), f-actin (green) and collagen I (red); scale bar $100 \mu \mathrm{m})$. 


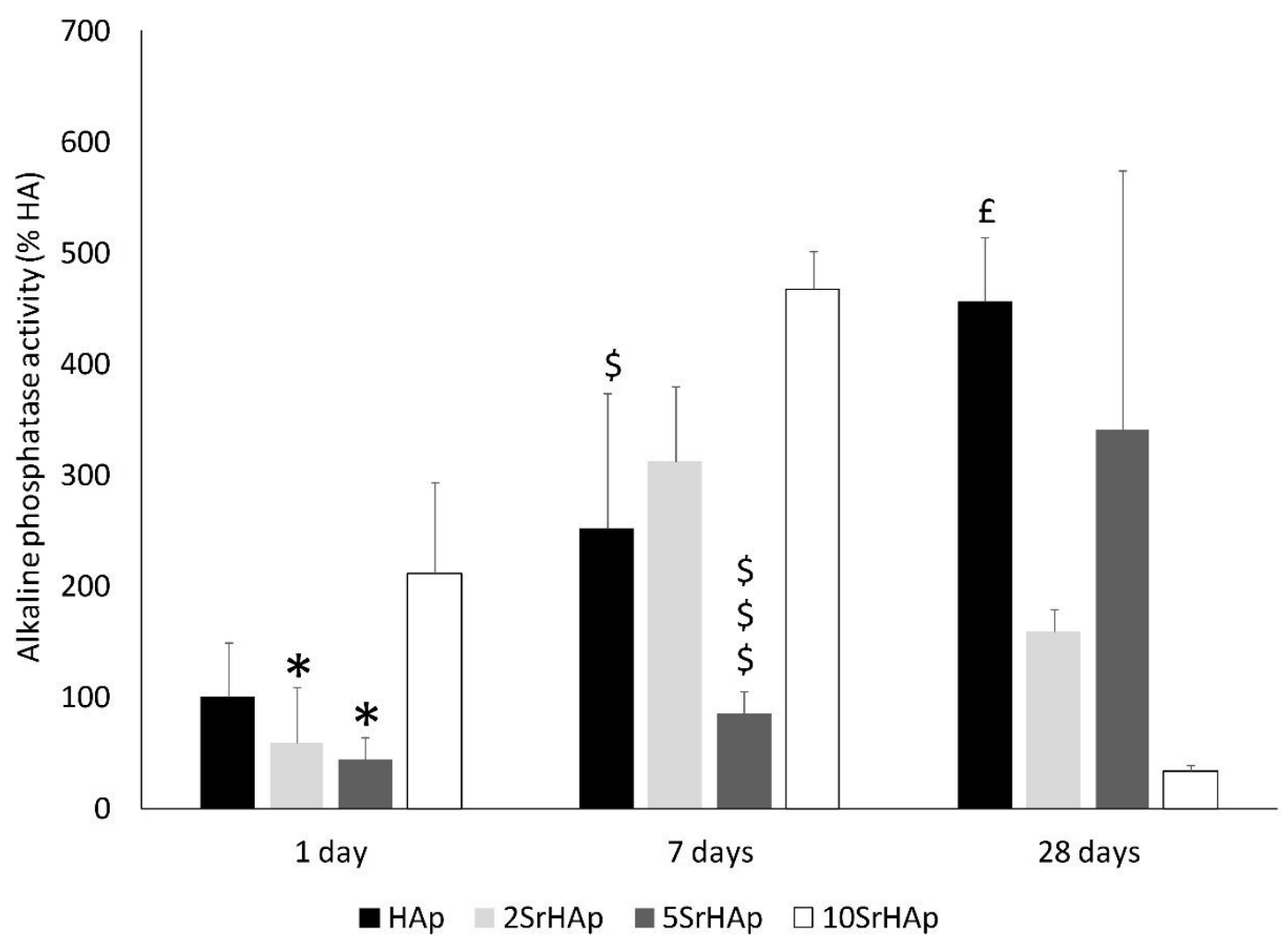

Figure 14. ALP activity of HOBC cultured in contact with HAp (control), 2SrHAp, 5SrHAp and 10SrHAp samples at 1,7 and 28 days. *: $\mathrm{p}<0.05$ compared to 10 SrHAp at day $1 ; \$: \mathrm{p}<0.05$, $\$ \$ \$:<0.001$ compared to 10 SrHAp at day $7 ; £: \mathrm{p}<0.05$ compared to $10 \mathrm{SrHAp}$ at day 28 .

\section{Discussion}

A range of SrHAp powders with nominal compositions comprising 1,2 and 5 at\% $\mathrm{Sr}$ (with respect to $[\mathrm{Sr} /(\mathrm{Sr}+\mathrm{Ca})] \cdot 100])$ and a pure $\mathrm{HAp}$ control have been synthesised using an aqueous precipitation method. Characterisation using AAS, FTIR, XRD, SEM/EDX, STEM/EDX and XPS showed the actual $\mathrm{Sr}$ contributions to be $0.56 \pm 0.06,1.41 \pm 0.14$ and $3.10 \pm 0.30 \mathrm{wt} \%$ (6.44 \pm $0.69,16.29 \pm 1.62$ and $36.15 \pm 3.50$ at\%), respectively. The stoichiometry of the SrHAp samples and HAp control were $1.67 \pm 0.02$ and $1.60 \pm 0.03$, as determined by EDX and XPS, respectively. SEM and TEM indicate the formation of rod-like crystals of average length $106 \pm 23 \mathrm{~nm}$ in all 
samples with the SrHAp samples also having flat crystals of $300 \mathrm{~nm}$ in length. The dimensions reported in this study are similar to those observed in previous work using an aqueous precipitation approach [32], [34]. Furthermore, the HAp material did not have any impurity phases or $\mathrm{CO}_{3}{ }^{2-}$ substitutions (corroborated by FTIR and XPS analyses), corresponding to a chemical formula of $\mathrm{Ca}_{10}\left(\mathrm{PO}_{4}\right)_{6}(\mathrm{OH})_{2}$, as would have been expected. By comparison, the SrHAp samples all showed the presence of levels of Sr-substitution that were significantly lower that the nominal values, as highlighted by the EDX and XPS results. The EDX also highlighted higher than expected $\mathrm{Ca} / \mathrm{P}$ and $(\mathrm{Ca}+\mathrm{Sr}) / \mathrm{P}$ ratios $(>1.67)$, whereas the XPS showed $\mathrm{Ca} / \mathrm{P}$ and $(\mathrm{Ca}+\mathrm{Sr}) / \mathrm{P}$ ratios lower than expected $(<1.67)$. However, it should be noted that XPS is a surface analysis technique and only obtains information from the top 5-10 nm of any sample, whereas EDX in this case was analysing over $1 \mu \mathrm{m}$ into the sample [25]. As such, it is suggested here that the material in the uppermost surface of the samples is non-stoichiometric (with a lower set of $\mathrm{Ca} / \mathrm{P}$ and $\mathrm{Ca}+\mathrm{Sr} / \mathrm{P}$ ratios) and differs from the bulk of the disks, which obviously show non-stoichiometry with higher than expected $\mathrm{Ca} / \mathrm{P}$ and $(\mathrm{Ca}+\mathrm{Sr}) / \mathrm{P}$ ratios. However, the differences here could be attributed to experimental error within both the EDX and XPS techniques, which can be as much as $10 \%$ in each case. Despite this, the $\mathrm{Sr} /(\mathrm{Ca}+\mathrm{Sr})$ ratios, observed in both the EDX and XPS results were in complete agreement, highlighting that the $\mathrm{Sr}$ levels increases from $2 \mathrm{SrHAp} \rightarrow 5 \mathrm{SrHAp} \rightarrow 10 \mathrm{SrHAp}$, as expected. Notably, the FWHM of the XRD peaks are seen to increase slightly with increasing levels of $\mathrm{Sr}$ (and are less well resolved), which indicates that the Sr-substituted materials are nanosized, as observed in previous work [32], [34]. These results are corroborated by the TEM analyses, showing the decrease in size of the crystallites with increasing Sr substitution in the samples. Previous research has highlighted that nanoscale HAp also has improved sintering and thermal densification properties, due to its increased surface area, which may improve its 
mechanical performance [38], [39]. Larger flatter crystals were also observed in the TEM results for the SrHAp samples, similar to those observed previously by Bigi et al. [36]. However, further analysis utilised STEM/EDX of the SrHAp samples (both the rod-like crystals and the larger flatter crystals show the presence of $\mathrm{Sr}$ in both crystal types). Further to this, the XRD results show a small shift to lower $2 \theta$ values, which is indicative of larger $\mathrm{Sr}^{2+}$ ions substituting for $\mathrm{Ca}^{2+}$ in the HAp lattice [21], [40], [41]. This is corroborated by the dehydroxylation observed in the FTIR spectra and the $\mathrm{Ca} / \mathrm{P},(\mathrm{Ca}+\mathrm{Sr}) / \mathrm{P}$ and $\mathrm{Sr} /(\mathrm{Ca}+\mathrm{Sr})$ ratios observed in the AAS, EDX and XPS results. Therefore it would be suggested that the SrHAp samples manufactured here have the chemical formula $\mathrm{Ca}_{10-\mathrm{x}} \mathrm{Sr}_{\mathrm{x}}\left(\mathrm{PO}_{4}\right)_{6}(\mathrm{OH})_{2}$. The purity and crystallinity of the SrHAp materials were largely as expected and confirmed the presence of low levels of Sr-substitution within the HAp lattice, as intended.

The higher ALP activity for 10SrHAp samples at earlier time points, i.e., 1 and 7 days, and significant reduction at 28 days suggest that osteoblasts are starting to form osteocytes by 28 days. This phenomenon, when $\mathrm{Sr}$ promotes the ultimate differentiation of human osteoblasts into osteocytes has previously been observed in a study with SrRan, an approved antiosteoporotic drug and is in line with the morphological changes observed [42]. ALP would be recognised as an early marker for osteogenic differentiation [43], as would collagen I [17]. Collagen I is an important initial bone matrix protein in new bone formation, and as shown here, the 10SrHAp sample has enhanced expression of collagen I, clearly undergoing significant reorganisation at 28 days. Indeed, Sr has been shown previously to increase collagen synthesis, without affecting matrix mineralisation, and the results obtained here for the 10SrHAp sample exhibit this phenomenon of increased collagen synthesis at 28 days [44]. Other reports in the literature also point out that although $\mathrm{Sr}$ has a positive effect on osteoblasts in vitro, it can inhibit mineralisation (by inhibiting 
crystal growth, enhancing the SrHAp solubility and disturbing Ca metabolism) [44], [45]. Interestingly in this study, with increasing Sr content, the SrHAp samples exhibited on average smaller nanocrystals (as shown in the TEM results), which would be in line with these expectations. However, in this in vitro study we would not have expected the HOBC to mineralise [44]. It is obvious that the 10SrHAp sample here exhibited the more positive in vitro response with respect to the ALP expression at the earlier time-points of 1 and 7 days, along with enhanced collagen expression and matrix re-organisation at 28 days. The AAS, EDX and XPS results showed that this sample had the highest level of Sr substitution in the HAp lattice, also exhibiting the lowest $\mathrm{Ca} / \mathrm{P}$ and $(\mathrm{Ca}+\mathrm{Sr}) / \mathrm{P}$ ratio in the uppermost surface of the disks, which may have facilitated enhanced dissolution of $\mathrm{Sr}$ into the surrounding media, resulting in the potential maturation of the osteoblasts into osteocytes. Further to this, as the crystal size decreases, so does the potential surface area, which facilitates enhanced dissolution of the materials. It is well documented that increased Sr substitution in the HAp lattice facilitates increased dissolution of the material [32], [34], and all the results here clearly show that this is optimised in the 10SrHAp sample. Importantly, as $\mathrm{Sr}$ content is the only variable between samples (given the phase purity and lack of other apparent ionic substitutions (namely $\left.\mathrm{CO}_{3}{ }^{2-}\right)$ ), the effects observed here can be attributed to $\mathrm{Sr}$ alone, which is a unique observation in the literature.

\section{Conclusions}

Hydroxyapatite with varying low levels of $\mathrm{Sr}$ substitution was synthesized and comprehensively characterized in order to evaluate the effect of these Sr concentrations on the physicochemical properties and interaction with primary human osteoblast cells. The results obtained clearly show the successful substitution of $\mathrm{Ca}^{2+}$ with $\mathrm{Sr}^{2+}$ ions in the hydroxyapatite lattice with levels significantly less than the nominal values. This has created a range of Sr- 
substituted hydroxyapatite materials with no other obvious impurities. In vitro results show that the samples with the highest actual $\mathrm{Sr}$ concentration have the highest early expression of alkaline phosphatase (days 1 and 7) and an enhanced expression of collagen I up to 28 days, clearly indicating the maturation of osteoblast cells into osteocytes indicative of the formation of new bone. Clearly the level of $\mathrm{Sr}$ substitution here is the discriminating factor that is driving the differentiation process of the osteoblasts. As such, these findings contribute to a better understanding of how the physicochemical properties Sr-substituted hydroxyapatite materials influence their in vitro (and in vivo) response in a manner that assists with the development of new therapeutic options.

\section{Acknowledgements}

The Authors would like to acknowledge funding from Invest Northern Ireland (INI) for the BioDevices Laboratory project.

This work has been supported by the European Regional Development Fund within the Activity 1.1.1.2 "Post-doctoral Research Aid" of the Specific Aid Objective 1.1.1 "To increase the research and innovative capacity of scientific institutions of Latvia and the ability to attract external financing, investing in human resources and infrastructure" of the Operational Programme "Growth and Employment" (No. 1.1.1.2/VIAA/2/18/339 and No 1.1.1.2/VIAA/1/16/045).

\section{Data Availability}

The raw/processed data required to reproduce these findings cannot be shared at this time as the data also forms part of an ongoing study. 


\section{References}

1. D.S. Gomes, A.M.C. Santos, G.A. Neves, R.R. Menezes, A brief review on hydroxyapatite production and use in biomedicine, Cerâmica 65 (2019) 282-302.

2. T. Winkler, F.A. Sass, G.N. Duda, K. Schmidt-Bleek, A review of biomaterials in bone defect healing, remaining shortcomings and future opportunities for bone tissue engineering, Bone Joint Res. 7 (2018) 232-243.

3. K.A. Blackwood, N. Bock, T.R. Dargaville, M.A. Woodruff, Scaffolds for growth factor delivery as applied to bone tissue engineering, International Journal of Polymer Science, Article ID 174942 (2012) 25 pages.

4. W. Wang, K.W.K. Yeung, Bone grafts and biomaterials substitutes for bone defect repair: A review, Bioact. Mater. 2 (2017) 224-247.

5. M. Šupová, Substituted hydroxyapatites for biomedical applications: A review, Ceram. Inter. 41(8) (2015) 9203-9231.

6. I. Cacciotti, Multisubstituted hydroxyapatite powders and coatings: The influence of the codoping on the hydroxyapatite performances. Int. J. Appl. Ceram. Technol. 16 (2019) 1864-1884.

7. J.H. Shepherd, D.V. Shepherd, S.M. Best, Substituted hydroxyapatites for bone repair, J. Mater. Sci. Mater. Med. 23 (2012) 2335-2347.

8. E. O’Neill, G. Awale, L. Daneshmandi, O. Umerah, K.W.-H. Lo, The roles of ions on bone regeneration, Drug Discov. Today 23 (2018) 879-890.

9. M. Pilmane, K. Salma-Ancane, D. Loca, J. Locs, L. Berzina-Cimdina, Strontium and strontium ranelate: Historical review of some of their functions, Mater. Sci. Eng. C 78 (2017) 1222-1230. 
10. M. Jiménez, C. Abradelo, J. San Románbc, L. Rojo, Bibliographic review on the state of the art of strontium and zinc based regenerative therapies. Recent developments and clinical applications, J. Mater. Chem. B 7 (2019) 1974-1985.

11. N.C. Lowry, The development of bioactive materials for orthopaedic implant devices. Ulster University, 2019.

12. W. Zhang, Y. Shen, H. Pan, K. Lin, X. Liu, B.W. Darvell, W.W. Lu, J. Chang, L. Deng, D. Wang, W. Huang, Effects of strontium in modified biomaterials, Acta Biomater. 7 (2011) 800-808.

13. S. Kargozar, M. Montazerian, E. Fiume, F. Baino, Multiple and promising applications of strontium ( $\mathrm{Sr}$ )-containing bioactive glasses in bone tissue engineering, Front. Bioeng. Biotech. 7:161 (2019) 1-29.

14. N. Neves, D. Linhares, G. Costa, C.C. Ribeiro, M.A. Barbosa, In vivo and clinical application of strontium-enriched biomaterials for bone regeneration: A systematic review, Bone Joint Res. 6 (2017) 366-375.

15. M. Baier, P. Staudt, R. Klein, U. Sommer, R. Wenz, I. Grafe, J. Meeder, P.P. Nawroth, C. Kasperk, Strontium enhances osseointegration of calcium phosphate cement: a histomorphometric pilot study in ovariectomized rats, J. Orthop. Surg.Res. 8 (2013) 1-8.

16. G. Hulsart-Billström, W. Xia, E. Pankotai, M. Weszl, E. Carlsson, C. Forster-Horvath, S. Larsson, H. Enggvist, Z. Lacsza, Osteogenic potential of Sr-doped calcium phosphate hollow spheres in vitro and in vivo, J. Biomed. Mater. Res. A 101A (2013) 2322-2331.

17. P. Naruphontjirakul, O. Tsigkou, S. Li, A.E. Porter, J.R. Jones, Human Mesenchymal stem cells differentiate into an osteogenic lineage in presence of strontium containing bioactive glass nanoparticles, Acta Biomater. 90 (2019) 373-392. 
18. C. Capuccini, P. Torricelli, F. Sima, E. Boanini, C. Ristoscu, B. Bracci, G. Socol, M. Fini, I.N. Mihailescu, A. Bigi, Strontium-substituted hydroxyapatite coatings synthesized by pulsed-laser deposition: In vitro osteoblast and osteoclast response, Acta Biomater. 4 (2008) 1885-1893.

19. M. Kavitha, R. Subramanian, R. Narayanan, V. Udhayabanu, Solution combustion synthesis and characterization of strontium substituted hydroxyapatite nanocrystals, Powder Technol. 253 (2014) 129-137.

20. E.M. Czekanska, M.J. Stoddart, R.G. Richards, J.S. Hayes, In search of an osteoblast cell model for in vitro research, Eur. Cell. Mater. 24 (2012) 1-17.

21. L. Robinson, K. Salma-Ancane, L. Stīpniece, B.J. Meenan, A.R. Boyd, The deposition of strontium and zinc co-substituted hydroxyapatite coatings, J. Mater. Sci. Mater. Med. 28 (2017) 51-64.

22. N. Döbelin, K. Reinhard, Profex: A graphical user interface for the Rietveld refinement program BGMN, J. Appl. Cryst. 48 (2015) 1573-1580.

23. S.A. Fawcett, J.M. Curran, R. Chen, N.P. Rhodes, M.F. Murphy, P. Wilson, L. Ranganath, J.P. Dillon, J.A. Gallagher, J.A. Hunt, Defining the properties of an array of $-\mathrm{NH}_{2}-$ modified substrates for the induction of a mature osteoblast/osteocyte phenotype from a primary human osteoblast population using controlled nanotopography and surface chemistry, Calcif. Tissue Int. 100 (2017) 95-106.

24. J.L. Ong, L.C. Lucas, G.N. Raikar, J.J. Weimer, J.C. Gregory, Surface characterization of ion-beam sputter-deposited Ca-P coatings after in vitro immersion, Colloid. Surf. A Physicochem. Eng. Asp. 87 (1994) 151-162. 
25. P. Lemoine, R.W. Lamberton, A.A. Ogwu, J.F. Zhao, P. Maguire, J. McLaughlin, Complementary analysis techniques for the morphological study of ultrathin amorphous carbon films, J. Appl. Phys. 11 (1999) 564-570.

26. L. Berzina-Cimdina, N. Borodajenko, Research of calcium phosphates using Fourier transform infrared spectroscopy, in: T. Theophile (Ed.), Infrared Spectroscopy - Materials Science, Engineering, and Technology, InTech, Rijeka, 2012, pp. 123-148.

27. M. Frasnelli, F. Cristofaro, V.M. Sglavo, S. Dirè, E. Callone, R. Ceccato, G. Bruni, A.I. Cornaglia, L. Visai, Synthesis and characterization of strontium-substituted hydroxyapatite nanoparticles for bone regeneration. Mater. Sci. Eng. C 71 (2017) 653-662.

28. A.R. Boyd, C. O'Kane, B.J. Meenan, Control of calcium phosphate thin film stoichiometry using multi-target sputter deposition, Surf. Coatings Technol. 233 (2013) 131-139.

29. A.S. Posner, A. Perloff, A.F. Diorio, Refinement of the hydroxyapatite structure, Acta Crystallogr. 11 (1958) 308-309.

30. G. Cheng, Y. Zhang, H. Yin, Y. Ruan, Y. Sun, K. Lin, Effects of strontium substitution on the structural distortion of hydroxyapatite by rietveld refinement and Raman Spectroscopy, Ceram. Int. 45 (2019) 11073-11078.

31. I. Cacciotti, Cationic and anionic substitutions in hydroxyapatite, in: I.V. Antoniac (Ed.), Handbook of bioceramics and biocomposites, Springer International Publishing, Switzerland, 2015, pp. 1-68.

32. N. Lowry, Y. Han, B.J. Meenan, A.R. Boyd, A.R. Strontium and zinc co-substituted nanophase hydroxyapatite, Ceram. Int. 43 (2017) 12070-12078. 
33. G. Cheng, Y. Zhang, H. Yin, Y. Ruan, Y. Sun, K. Lin, Effects of strontium substitution on the structural distortion of hydroxyapatite by Rietveld refinement and Raman Spectroscopy, Ceram. Int. 45(8) (2019) 11073-11078.

34. N. Lowry, M. Brolly, Y. Han, S. McKillop, B.J. Meenan, A.R. Boyd, Synthesis and characterisation of nanophase hydroxyapatite co-substituted with strontium and zinc, Ceram. Int. 44 (2018) 7761-7770.

35. L.M. Silva, D.S. Menezesa, S. Narayananb, T. Shokuhfarb, R. Shahbazian-Yassarb, G.M.L. Dalmônicoc, J. Werckmannc, M. Farinad, E.A. dos Santosa, Counterions present in syntheses induce the precipitation of two different populations of Sr-containing hydroxyapatite crystals, Ceram. Int. https://doi.org/10.1016/j.ceramint.2019.10.177

36. A. Bigi, E. Boanini, C. Capuccini, M. Gazzano, Strontium-substituted hydroxyapatite nanocrystals, Inorganica Chim. Acta 360 (2007) 1009-1016.

37. T.A. Franz-Odendaal, B.K. Hall, P.E. Witten, Buried alive: How osteoblasts become osteocytes, Dev. Dynam. 235 (2006) 176-190.

38. H. Zhou, J. Lee, Nanoscale hydroxyapatite crystals for bone tissue engineering. Acta Biomater. 7 (2011) 2769-2781.

39. S.V. Dorozhkin, Nanosized and nanocrystalline calcium orthophosphates, Acta Biomater. 6 (2010) 715-734.

40. A.R. Boyd, L.D. Randolph, L. Rutledge, B.J. Meenan, Strontium-substituted hydroxyapatite coatings deposited via a co-deposition sputter technique, Mater. Sci. Eng. C 46 (2015) 290300.

41. A.R. Boyd, L. Rutledge, L.D. Randolph, I. Mutreja, B.J. Meenan, The deposition of strontium-substituted hydroxyapatite coatings, J. Mater. Sci. Mater. Med. 26 (2015) 1-14. 
42. P. Ammann, B. Robin, J.P. Bonjour, I. Tupinon-Mathieu, J.M. Meyer, R. Rizzoli, Long-term exposure to strontium ranelate dose-dependently increases bone strength in intact female rats, Bone 28 (2001) S220.

43. M. Tsai, W. Li, R.S. Tuan, W.H. Chang, Modulation of Osteogenesis in human mesenchymal stem cells by specific pulsed electromagnetic field stimulation, Int. J. Orthop. Res. 27 (2009) 1169-1174.

44. M. Tian, F. Chen, W. Song, Y. Song, Y. Chen, C. Wan, X. Yu, X. Zhang, In vivo study of porous strontium doped calcium polyphosphate scaffolds for bone substitute applications, J. Mater. Sci. Mater. Med. 20 (2009) 1505-1512.

45. D.P. Wornham, M.O. Hajjawi, I.R. Orriss, T.R. Arnett, Strontium potentially inhibits mineralisation in bone forming primary rat osteoblast cultures and reduces numbers of osteoclasts in mouse marrow cultures, Osteoporosis Int. 25 (2014) 2477-2484. 